\title{
A C-Terminal Determinant of GluR6 Kainate Receptor Trafficking
}

\author{
Sheng Yan, ${ }^{1}$ James M. Sanders, ${ }^{1}$ Jian Xu, ${ }^{2}$ Yongling Zhu, ${ }^{2}$ Anis Contractor, ${ }^{2}$ and Geoffrey T. Swanson ${ }^{1}$ \\ ${ }^{1}$ Department of Pharmacology and Toxicology, University of Texas Medical Branch, Galveston, Texas 77555, and ${ }^{2}$ Molecular Neurobiology Laboratory, The \\ Salk Institute, La Jolla, California 92037
}

\begin{abstract}
Intracellular trafficking of ionotropic glutamate receptors is regulated predominantly by determinants in the cytoplasmic C-terminal domain of the subunit proteins. Although AMPA receptors are found at the vast majority of excitatory synapses, synaptic kainate receptors exhibit a much more restricted distribution, suggesting that specific mechanisms exist for selective trafficking of these receptor proteins. In this report, we define a critical forward trafficking motif that is necessary for surface expression of the glutamate receptor 6 (GluR6) kainate receptor as well as chimeric proteins containing only the GluR6 C-terminal domain. The trafficking determinant was identified by tracking surface expression of green fluorescent protein-tagged GluR6 receptors with confocal immunofluorescence in COS-7 cells and cultured neurons and patch-clamp electrophysiology in human embryonic kidney 293 cells. Serial truncation and alanine site mutagenesis of the GluR6 subunit C terminus localized the critical motif to a seven amino acid stretch of predominantly basic residues. Alanine mutation of the trafficking motif reduced kainate receptor current amplitudes by $>90 \%$ and resulted in retention of the mutated receptors in the endoplasmic reticulum. This forward trafficking domain is the first such identified for kainate receptors.
\end{abstract}

Key words: glutamate receptor; kainate receptor; trafficking; endoplasmic reticulum; patch clamp; immunofluorescence

\section{Introduction}

Fast excitatory transmission in the mammalian brain is mediated by ionotropic glutamate receptors, which are ligand-gated ion channels composed of tetrameric assemblies of AMPA, kainate (KA), or NMDA subunits. These receptor subunit proteins have been described as "modular" proteins because different structural domains in the receptor proteins appear to subserve distinct functions (Madden, 2002). The C-terminal domains of the receptor subunits, which are cytoplasmic, contain critical determinants of subcellular receptor localization. Regulation of receptor trafficking by these determinants ensures that only fully assembled multimeric receptors are expressed on the plasma membrane. For example, an arginine-based (RXR) endoplasmic reticulum (ER) retention/retrieval motif causes retention of some splice variants of the NMDA receptor subunit NR1 in the ER (Standley et al., 2000; Scott et al., 2001). RXR motifs similarly function as retention/retrieval motifs in a number of integral membrane proteins, including G-protein-coupled $\mathrm{K}^{+}$channels and $\mathrm{GABA}_{\mathrm{B}}$ receptors (Zerangue et al., 1999; Margeta-Mitrovic et

Received June 19, 2003; revised Nov. 14, 2003; accepted Nov. 14, 2003.

This work was supported by grants from the National Institute of Mental Health (NIMH) (R03 MH065289) and National Institute of Neurological Disorders and Stroke (R01 NS44322) to G.T.S., a grant from NIMH (R03 MH65632) to A.C., and a National Institute on Drug Abuse predoctoral award to J.M.S. The support of the National Institute of Environmental Health Sciences Center and the Optical Imaging Laboratory at University of Texas Medical Branch is also appreciated. We thank Dr. John Marshall for the generous donation of the Tac-R6, myc-KA2, and myc-KA2 $\triangle R 6$ DNAs used in the study, Dr. Andrea Ghetti for GFP-GluR6 DNA, and Dr. Lokanatha Valluru for technical support.

Correspondence should be addressed to Dr. Geoffrey T. Swanson, Department of Pharmacology and Toxicology, University of Texas Medical Branch, 301 University Boulevard, Galveston, TX 77555. E-mail: g.swanson@utmb.edu.

A. Contractor's present address: Department of Physiology, Feinberg School of Medicine, Northwestern University, Chicago, IL 60611.

DOI:10.1523/JNEUROSCI.4985-03.2004

Copyright $\odot 2004$ Society for Neuroscience $\quad$ 0270-6474/04/240679-13\$15.00/0 al., 2000; Pagano et al., 2001; Ma et al., 2002). The C-terminal domain of ionotropic glutamate receptors is also the site of activity-dependent modulation of cycling through endosomal compartments, which underlies some forms of long-term synaptic plasticity (Malinow and Malenka, 2002). This modulation is driven by complex interactions of receptor subunit C-terminal domains with a set of proteins that include PDZ proteins [e.g., GRIP (glutamate receptor interacting protein) and PICK1 (protein interacting with c-kinase)] (Hayashi et al., 2000; Shi et al., 2001) and $\mathrm{N}$-ethylmaleimide sensitive factor (NSF) (Nishimune et al., 1998; Song et al., 1998; Shi et al., 2001).

Cytoplasmic determinants of kainate receptor trafficking are not characterized as well as those in AMPA and NMDA receptors. The mammalian kainate receptor gene family consists of five subunits: glutamate receptor (GluR) 5, GluR6, GluR7, KA1, and KA2 (Hollmann and Heinemann, 1994). Expression of recombinant kainate receptor subunits revealed that "low-affinity" kainate receptors (GluR5-7) formed functional homomeric receptors in heterologous expression systems (for review, see Dingledine et al., 1999). GluR6 receptors, in particular, express at very high levels in the plasma membrane. KA1 and KA2 subunits, in contrast, do not form functional homomeric channels, but rather assemble with GluR5, -6, or -7 to form heteromeric receptors with distinct kinetic and pharmacological properties (Herb et al., 1992; Schiffer et al., 1997).

In this project, we found C-terminal trafficking determinants in the GluR6 kainate receptor subunit responsible for the efficient targeting of homomeric kainate receptors to the plasma membrane. Truncated and site mutants of green fluorescent protein (GFP)-GluR6 subunits lacking portions of the C-terminal tail were assayed for surface expression using electrophysiological 
recordings and confocal immunofluorescence. We found that robust surface expression of GluR6 receptors was dependent on a minimal motif composed predominantly of basic residues in the medial portion of the C-terminal tail as well as a cysteine residue shown previously to be a substrate for palmitoylation (Pickering et al., 1995). This basic domain is a critical component for forward trafficking of the GluR6 subunit and therefore represents an important determinant of kainate receptor function.

\section{Materials and Methods}

Molecular biology. The N-terminal tagged GFP-GluR6 subunit was generated by Dr. Andrea Ghetti (Salk Institute, La Jolla, CA) by inserting cDNA encoding green fluorescent protein after the codon for threonine 33 in the GluR6 subunit cDNA. Alanine scanning and introduction of stop codons to create truncation mutants were performed using the QuikChange site mutagenesis protocol (Stratagene, La Jolla, CA). All the mutations were verified by DNA sequencing.

Electrophysiology. Human embryonic kidney (HEK) 293 cells were maintained in DMEM/F12 media supplemented with $10 \%$ fetal bovine serum and $1 \%$ penicillin/streptomycin. One day before transfection, cells were split onto $12 \mathrm{~mm}$ glass coverslips coated with $100 \mu \mathrm{g} / \mathrm{ml}$ collagen and poly-D-lysine at low density. Cells were transfected the following day using the FuGene 6 reagent according to the manufacturer's protocol (Roche Applied Science, Indianapolis, IN). Receptor cDNAs were transfected in combination with a plasmid DNA containing enhanced GFP (typically 0.3 and $0.1 \mu \mathrm{g}$, respectively). Patch-clamp recordings from transfected cells were made $24-72 \mathrm{hr}$ later. Cells were visualized with a Zeiss Axioskop FS2 microscope (Carl Zeiss, Thornwood, NY) and recordings were made using an Axopatch 200B amplifier and pClamp 8 software (Axon Instruments, Foster City, CA). Borosilicate patch electrodes had series resistances of 1.5-2.5 M . Extracellular solution contained (in mM): $150 \mathrm{NaCl}, 2.8 \mathrm{KCl}$, $1.8 \mathrm{CaCl}_{2}, 1.0 \mathrm{MgCl}_{2}$, and $10 \mathrm{HEPES}$ (adjusted to $\mathrm{pH} 7.3$ ). Intracellular solutions contained (in mM): $110 \mathrm{CsF}, 30 \mathrm{CsCl}, 4 \mathrm{NaCl}, 0.5 \mathrm{CaCl}_{2}, 10 \mathrm{HEPES}$, and 5 EGTA (adjusted to $\mathrm{pH} 7.3$ ). After whole-cell configurations were obtained, cells were lifted from the coverslip into a laminar stream of extracellular solution. Glutamate $(10 \mathrm{~mm})$ was applied by rapid translation of a three-barrel glass flow pipe glued to a piezoceramic bimorph; translation was driven by a digital pulse from a stimulation-isolation unit (Winston Electronics, Millbrae, CA) controlled by Clampex software (Axon Instruments). Analysis was performed off-line using Clampfit software (Axon Instruments).

Immunolocalization of receptors. COS-7 cells were transfected using FuGene 6 transfection reagent (Roche Applied Science) following the manufacturer's recommended protocol. Surface and intracellular protein expression were analyzed $48 \mathrm{hr}$ after transfection. For detection of cell-surface receptors, transfected cells were incubated with polyclonal anti-GFP antibody (1:500; Chemicon, Temecula, CA), polyclonal antimyc antibody (1:500; Upstate Biotechnology, Lake Placid, NY), or monoclonal anti-Tac antibody (1:1000; COVANCE, Richmond, CA) for $1 \mathrm{hr}$ at $4^{\circ} \mathrm{C}$. The cells were washed with cold PBS and fixed with $4 \%$ paraformaldehyde/4\% sucrose in PBS for $20 \mathrm{~min}$ at room temperature (RT). After fixation, the cells were washed with PBS and incubated with fluorescence-conjugated goat secondary antibodies (Alexa Fluor antibodies; Molecular Probes, Eugene, OR) for $1 \mathrm{hr}$ at RT For colocalization of receptors with intracellular organelles, transfected cells were fixed in $4 \%$ paraformaldehyde $/ 4 \%$ sucrose in PBS for $20 \mathrm{~min}$ at RT and permeabilized with $0.2 \%$ Triton X-100 in PBS for 5 min. After several washes with PBS, the cells were incubated with primary antibodies for $2 \mathrm{hr}$ at RT [monoclonal anti-protein disulfide isomerase (PDI), 1:200, Affinity Bioreagents, Golden, CO; polyclonal anti-giantin, 1:1000, COVANCE]. After washing with PBS, the cells were incubated with fluorescenceconjugated secondary antibody (Alexa Fluor 594, Molecular Probes) for $1 \mathrm{hr}$ at RT Surface and intracellular immunofluorescence were captured with a Zeiss LSM510 confocal microscope (Carl Zeiss). Representative images of surface-expressed receptors shown in most of the figures are projections of $10-15$ optical slices with a thickness of $0.38-0.45 \mu \mathrm{m}$ (the exact thickness was optimized for each cell by the Zeiss LSM software).
The colocalization images shown in Figures 1 and 5 are single optical slices with thickness of $0.38-0.40 \mu \mathrm{m}$.

Enzyme-linked immunosorbent assays. Enzyme-linked immunosorbent assays (ELISAs) were performed using a modified version of a previously described protocol (Nong et al., 2003). Briefly, DMEM media was removed from transfected COS-7 cells cultured in 12-well plates, and cells were washed once with ice-cold PBS. Cells were incubated at $4^{\circ} \mathrm{C}$ with anti-myc or anti-Tac monoclonal antibody for $30 \mathrm{~min}$ at $4^{\circ} \mathrm{C}$ (antic-myc 9E10, 1:100, Roche Applied Science; anti-Tac, 1:1000, COVANCE; antisera diluted in DMEM/10\% FBS), washed extensively with ice-cold PBS, and fixed for $20 \mathrm{~min}$ at RT with $4 \%$ paraformaldehyde in PBS. After washing with PBS, the cells were incubated for $1 \mathrm{hr}$ at RT with goat anti-mouse antibody conjugated to horseradish peroxidase (HRP) (1:1000; Amersham Biosciences, Piscataway, NJ). Cells were again washed with PBS, the HRP substrate $o$-phenylenediamine dihydrochoride was added, and the color reaction was developed for 2-3 hr (antimyc) or $\sim 30 \mathrm{~min}$ (anti-Tac). The optical density of $1 \mathrm{ml}$ of supernatant was read on a spectrophotometer at $492 \mathrm{~nm}$. Values for cell surface expression of kainate receptors were determined by averaging at least four replicates in each experiment and subtracting the mean absorbance in wells with nontransfected cells. Three separate experiments were performed with each set of receptor cDNAs.

Protein preparation, immunoblotting, and immunoprecipitation. COS-7 cells were transfected with FuGene 6 reagent in six-well plates or $100 \mathrm{~mm}$ dishes; $48 \mathrm{hr}$ later the cells were washed twice with cold PBS and lysed in 0.1 or $0.5 \mathrm{ml} \mathrm{lysis} \mathrm{buffer} \mathrm{(} 50 \mathrm{~mm}$ Tris, $150 \mathrm{~mm} \mathrm{NaCl}, 0.5 \% \mathrm{NP}-40$, 2 mм 4-(2-Aminoethyl)-benzenesulfonylfluoride-HCl, 1 mм EDTA, 130 $\mu \mathrm{M}$ bestatin, $14 \mu \mathrm{M}$ L-trans-epoxysuccinyl-leucylamido(4-guanidino)butane, $1 \mathrm{~mm}$ leupeptin, $0.3 \mu \mathrm{M}$ aprotinin). Supernatants were obtained after lysis and centrifugation at $15,000 \mathrm{rpm}$ at $4^{\circ} \mathrm{C}$ for $20 \mathrm{~min}$. Protein expression levels were assessed after loading equal amounts of total protein for $8 \%$ SDS-PAGE separation and Western blotting with anti-GFP and antiactin antibodies (Santa Cruz Biotechnology, Santa Cruz, CA). Immunoprecipitations were performed by incubating lysate supernatants with 2.5 $\mu \mathrm{g}$ of anti-GFP antibody (JL-8; BD Biosciences Clontech, Palo Alto, CA) for $2 \mathrm{hr}$ at $4^{\circ} \mathrm{C}$, followed by incubation with $50 \mu \mathrm{l}$ of $50 \%$ protein $\mathrm{A} / \mathrm{G}$ Sepharose (Amersham Biosciences) slurry overnight. After four washes in lysis buffer, bound proteins were eluted from the beads by boiling in $2 \times$ sample buffer and then separated by electrophoresis on $8 \%$ SDSPAGE gels. Proteins were electrotransferred onto nitrocellulose membranes and probed with anti-GFP antibody (1:1000, JL-8; BD Biosciences Clontech) anti-GluR6/7 antibody $(0.1 \mu \mathrm{g} / \mathrm{ml}$; Upstate Biotechnology). Immunoreactive bands were visualized using HRP-conjugated donkey anti-rabbit or goat anti-mouse secondary antibody with the enhanced chemiluminescence detection technique (Amersham Biosciences).

Pulse-chase assays. HEK 293 cells were transfected with plasmid DNA using Lipofectamine reagent (Invitrogen, Carlsbad, CA). After $36 \mathrm{hr}$, cells were incubated in cysteine- and methionine-free DMEM starvation media for $30 \mathrm{~min}$. Starvation media was removed and replaced with DMEM labeling media containing EXPRE ${ }^{35} \mathrm{~S}^{35} \mathrm{~S}$ protein labeling mix (PerkinElmer Life Sciences, Boston, MA). After $30 \mathrm{~min}$, cells were rinsed twice with PBS and returned to normal growth media including brefeldin A (10 $\mu \mathrm{g} / \mathrm{ml}$; Calbiochem, La Jolla, CA) and methionine for the duration of the chase to the specified time points. Cells were washed twice with ice-cold PBS and incubated on ice for $10 \mathrm{~min}$ in lysis buffer $(50 \mathrm{~mm}$ HEPES, pH 7.4, $150 \mathrm{~mm} \mathrm{NaCl}, 1 \%$ Triton X-100) with a mixture of protease inhibitors (Roche Applied Science), after which solubilized extracts were collected for immunoprecipitation. Proteins were immunoprecipitated with monoclonal anti-GFP antibody (3E6; Molecular Probes), resolved with SDS-PAGE, and quantified on a Molecular Dynamics Phosphorimager 425S (Amersham Biosciences). The measured densities at each time point were normalized to the image density at time point zero.

Radioligand binding assays. Crude membrane fractions were prepared from transiently transfected COS-7 cells by first homogenizing in buffer (50 mu Tris-Cl, $0.32 \mathrm{~m}$ sucrose, $\mathrm{pH} 7.4$ ), centrifugation at $800 \times g$ for 10 $\min$ at $4^{\circ} \mathrm{C}$, and recentrifugation of the supernatant at $13,000 \times g$ for 20 $\min$ at $4^{\circ} \mathrm{C}$. The pellet was resuspended in $2 \mathrm{ml}$ of homogenizing buffer, and the process was repeated twice. The final membrane pellet was re- 
suspended in $50 \mathrm{~mm}$ Tris- $\mathrm{Cl}, \mathrm{pH}$ 7.4, for use in radioligand binding assays. For homologous displacement assays, cold SYM2081 $(0.1-1 \mu \mathrm{M})$ was used to displace $10 \mathrm{~nm}\left[{ }^{3} \mathrm{H}\right]$ SYM2081 (Tocris Cookson, Ellisville, $\mathrm{MO}$ ) from binding to $25 \mu \mathrm{g}$ of membrane protein. Nonspecific binding was measured in the presence of $1 \mathrm{~mm}$ glutamate. Binding was performed for $1 \mathrm{hr}$ at $4^{\circ} \mathrm{C}$ before rapid filtration on Whatman GF/C glass filters through a Brandel Cell Harvester (Biomedical Research and Development Laboratories, Gaithersburg, MD), three washes with cold $0.9 \%$ saline solution, addition of scintillation fluid, and counting on a Beckman LS5000 TD scintillation counter (Beckman Instruments, Fullerton, CA).

Neuronal cell culture, transfection, and imaging. Hippocampal neurons from postnatal day 0 rats were cultured using the methods described previously (Murthy et al., 1997). After $3 \mathrm{~d}$ in culture, cells were transfected using the calcium phosphate method (Xia et al., 1996). Transfected cultures were allowed to grow for another week. Immunocytochemistry was performed when cells were $10 \mathrm{~d}$ in vitro. To label cell extracellular GFP, living cells were incubated with chicken anti-GFP polyclonal antibody (1:500; Chemicon) for $20 \mathrm{~min}$ at $37^{\circ} \mathrm{C}$, rinsed twice with PBS, and fixed with $4 \%$ paraformaldehyde $/ 4 \%$ sucrose in PBS. Cells were then blocked in PBS containing $10 \%$ BSA overnight at $4^{\circ} \mathrm{C}$ and incubated with Alexa Fluor 568 goat anti-chicken IgG (1:500; Molecular Probes) for $2 \mathrm{hr}$ at RT. The coverslips were rinsed extensively with PBS and mounted. Neurons were observed on an LSM510 Zeiss confocal laser scanning microscope. Images were analyzed by using Simple PCI Image Analysis System (Compix Inc., Cranberry Township, PA). Regions of interest (ROIs) were drawn around the fluorescent cell bodies, and the average pixel intensity was calculated. To correct the background, equivalent ROIs were drawn outside the fluorescent neurons in the same image, and the average pixel intensities were subtracted from the neuronal fluorescence. Fluorescence is expressed in intensity units per pixel, and data are presented as mean \pm SEM.

\section{Results}

To study C-terminal determinants of kainate receptor trafficking, we assessed surface expression levels of truncation and site mutants of an N-terminal GFP-tagged GluR6 subunit qualitatively after expression in COS-7 cells with immunofluorescent labeling and quantitatively with patch-clamp electrophysiological current recording from receptors expressed in HEK 293 cells. Wild-type GFP-GluR6 subunits expressed well as homomeric kainate receptors in COS-7 cells, exhibiting robust surface labeling when nonpermeabilized cells were probed with anti-GFP antisera (Fig. 1A). N-terminal GFP tagging of GluR6 did not alter the amplitude or the kinetics properties of the kainate receptor channel (Bowie et al., 2003) (data not shown).

We first generated serial truncations of the GFP-GluR6 subunit. Expression of eight receptor cDNAs with introduced stop codons produced the truncation mutants spanning the C-terminal tail as illustrated in Figure $1 B$. Our terminology for these truncation mutants indicates the position at which a stop codon was introduced (that is, truncation R6-880stop has residue 879 as the last amino acid). This figure also details our qualitative measure of the relative surface expression of each of the truncation mutants (plus marks on the right side). In this scale, three plus marks indicate a surface expression level indistinguishable from GFP-GluR6, two plus marks indicates weaker surface staining on most transfected cells, and one plus mark denotes extremely weak surface staining apparent only in a subset of transfected cells. Representative examples of each type of staining are shown in Figure $1 C$. The four longest truncation mutants shown in Figure 1B-R6-880stop, R6-887stop, R6-896stop, and R6-904stop-exhibited strong surface labeling, indicating that trafficking of these receptors was relatively unaffected by the loss of the last 28 amino acids of the $\mathrm{C}$ terminus. We did note that these mutant receptors tended to have a more punctate anti-GFP surface staining than GFP-GluR6 (e.g., compare R6-880stop in
Fig. $1 C$, right panel, and GFP-GluR6 in Fig. $1 A$ ). Two of the truncated subunits, R6-868stop and R6-874stop, exhibited much lower levels of surface anti-GFP immunofluorescence than GFP-GluR6 (Fig. 1C, center panel); their total GFP fluorescence remained distributed primarily in reticular organelles. A more significant reduction in surface expression was observed on truncation of a large proportion of the $\mathrm{C}$ terminus in mutant receptors R6-850stop and R6-854stop; surface immunofluorescence for these receptors was very weak and only detectable in a subset of cells imaged (Fig. 1C, left panel). In addition, the intracellular receptor distribution appeared different in a large proportion of transfected cells: although some fluorescence arose from reticular structures, a large fraction of GFP fluorescence was located in punctate clusters and dense perinuclear compartments. Both GFP-GluR6 and R6-850stop receptors showed extensive colocalization with the ER marker PDI (Fig. 1D); however, the densest puncta of GFP fluorescence did not appear to colocalize with PDI. In contrast to the GFP-GluR6 subunit, R6-850stop protein did not colocalize with immunoreactivity for giantin, a cis- and medial-Golgi resident protein (Fig. $1 D$ ). Thus, truncation of the GluR6 C terminus causes accumulation of the receptor protein in the ER and unidentified organelles. These results suggest that two separate trafficking domains were localized in the $\mathrm{C}$ terminus of GluR6 subunits. First, an ER or Golgi exit motif, or both, was located between residues 868 and 880 , because truncation at 868 produced a predominantly ER distribution (with very little surface expression), whereas R6-880stop exhibited a strong surface labeling similar to full-length GFP-GluR6. Second, a different trafficking or oligomerization motif was located between residues 854 and 868; deletion of this domain caused an altered intracellular distribution into compartments that were not reticular (and which have not been identified), perhaps representing aberrant targeting, accumulation in ER-Golgi intermediate compartments, ER fragmentation, or protein movement into putative degradation pathways. In our subsequent series of experiments, we focused on the putative forward trafficking between residues 868 and 880 .

We quantified the surface expression of these truncation mutants using patch-clamp recording from transfected HEK 293 cells. Glutamate (10 mM) was fast-applied to individual cells lifted from the coverslip. Representative currents evoked by a $100 \mathrm{msec}$ glutamate application are shown in Figure $2 \mathrm{~A}$. As observed previously, homomeric GFP-GluR6 kainate receptors gated robust currents of large amplitude $(10.15 \pm 1.01 \mathrm{nA} ; n=25$; holding potential $-70 \mathrm{mV})$. In agreement with immunofluorescent results, R6-850stop receptors gated very small currents in response to glutamate in a subset of transfected cells $(0.24 \pm 0.06 \mathrm{nA} ; n=$ 11). Current amplitudes from R6-868stop receptors were larger but remained $<10 \%$ of GFP-GluR6 amplitudes $(0.72 \pm 0.24 \mathrm{nA}$; $n=10)$. In contrast, R6-880stop current amplitudes were similar to GFP-GluR6 receptors $(7.4 \pm 1.0 \mathrm{nA} ; n=18)$. These data, along with that gathered from expression of R6-854stop, R6874 stop, and R6-887stop receptors, are shown in the histogram in Figure $2 B$ (mean amplitudes in nanoamperes for R6-854stop, $0.01 \pm 0.03$; R6-874stop, $1.50 \pm 0.39$; R6-887stop, $7.72 \pm 0.86$; $n=5,13$, and 14 , respectively). In summary, functional analysis of these truncation mutants supports our initial conclusion garnered from immunofluorescent observations that amino acids 868 and 880 define the boundaries of a domain in the GluR6 subunit containing a critical determinant for surface expression.

It is possible that inefficient protein expression or oligomerization accounts for the reduction in surface immunofluorescence and whole-cell currents with the shorter truncation mu- 
A GFP-GluR6
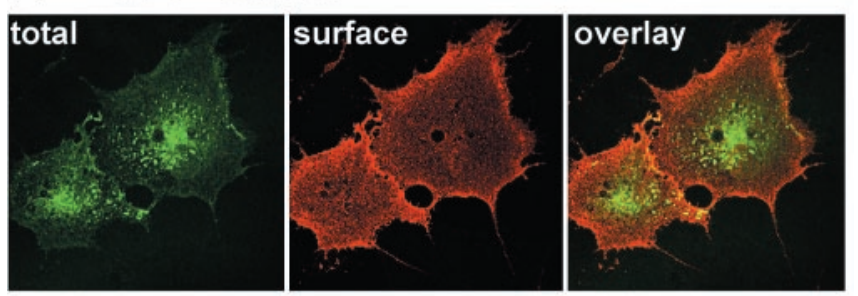

B GFP-GluR6 truncations

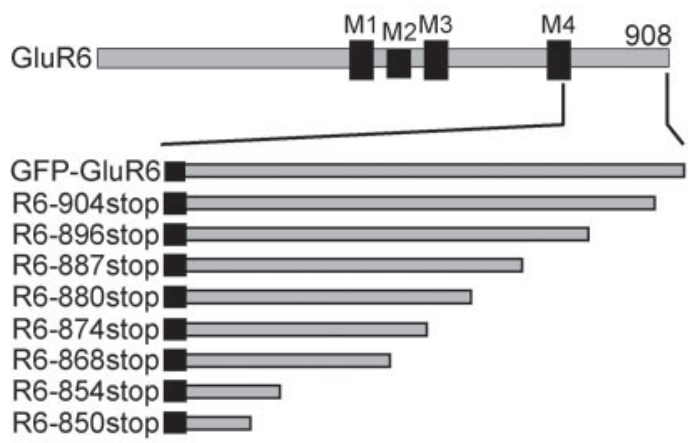

surface expression
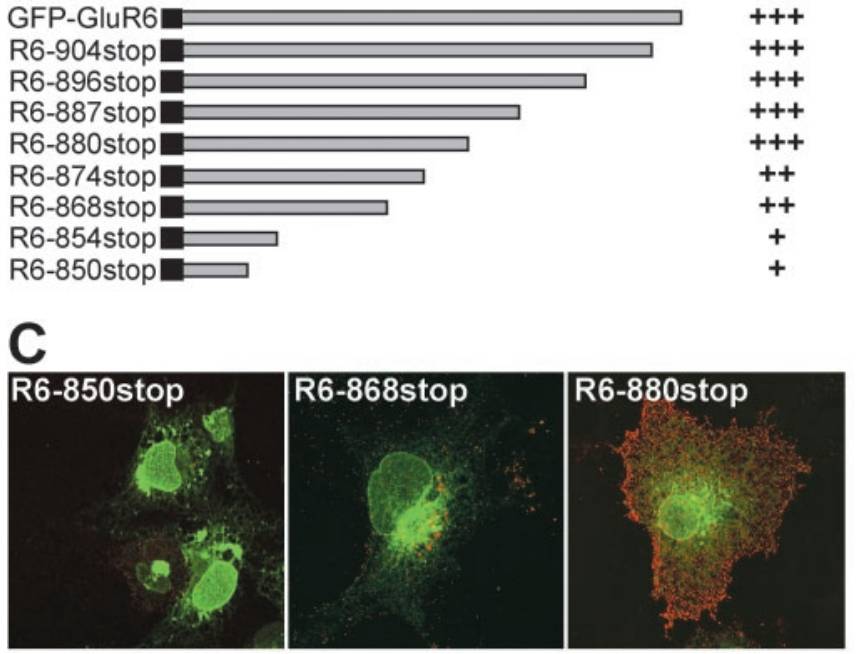

D
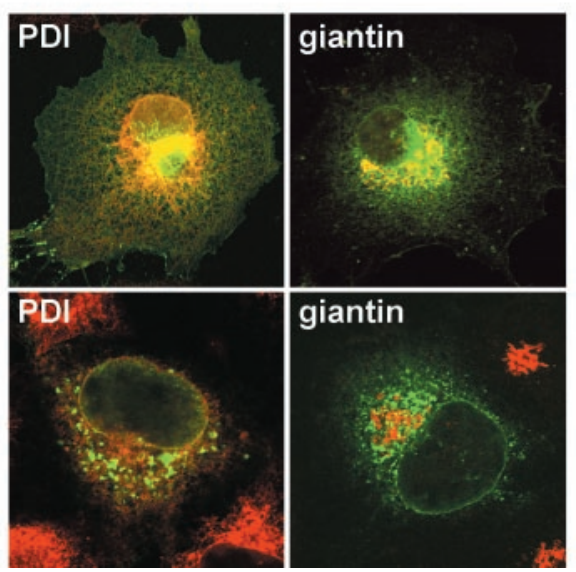

Figure 1. Serial truncations of the GluR6 C terminus define the borders of a trafficking domain. A, GFP-tagged GluR6 kainate receptors expressed in COS-7 cells are expressed on the plasma membrane. Nonpermeabilized cells were incubated with anti-GFP antibody before fixation to label surface receptors (red). The green fluorescence arises from total GFP-GluR6. The confocal images are projections from stacks of optical sections. $B$, A diagram illustrating the serial truncations made in the C-terminal tail of the GFP-GluR6 subunit. The C-terminal tail is cytoplasmic and follows the fourth membrane domain (M4 in the diagram). Stop codons were constructed in CDNA to generate eight truncated receptors as shown after expression in COS-7 and HEK 293 cells. On the right we show qualitative assessments of the level of surface staining compared with GFP-GluR6: +++ , indistinguishable from GFP-GluR6; ++ , marked reduction from GFP-GluR6 levels; + , surface staining faint or undetectable in the majority of transfected cells. Note that R6-868stop and R6-880stop define a region with truncation that causes the surface expression of GluR6 to go from wild type to very low levels. C, Representative confocal images from the three qualitative levels of surface expression from receptors expressed tants. To test these alternatives, we first measured protein expression levels on Western blots containing total protein isolated from COS-7 cells expressing GFP-GluR6, R6-850stop, R6-854stop, R6-868stop, R6-874stop, and R6-880stop receptors (Fig. 2C). Anti-actin immunoreactivity in the same lanes served as internal controls for protein density. As shown in Figure 2 , there were no apparent differences in the total levels of expression of any of the truncation mutants that might account for a reduction in surface receptors. We also tested for coassembly of R6-850stop subunits with wild-type GluR6 receptor subunits in coimmunoprecipitation experiments in which heteromeric R6850stop/GluR6 kainate receptor complexes were precipitated with anti-GFP (which recognized GFP-tagged R6-850stop) and then probed in Western blots with an anti-GluR6/7 antibody directed against a C-terminal epitope (which recognized GluR6 but not R6-850stop subunits) (Fig. 2D). GluR6 immunoreactivity was detectable after precipitation of the R6-850stop protein (Fig. 2D, IP lane), indicating that the subunits were coassembled into heteromeric complexes. We also observed that cotransfection of R6-850stop with wild-type GluR6 in COS-7 cells significantly increased surface expression of anti-GFP immunoreactivity (arising from GFP-tagged R6-850stop protein), again demonstrating that R6-850stop/GluR6 heteromers were assembled and located on the plasma membrane, in contrast to homomeric R6-850stop receptors (Fig. 2E). Finally, to test whether truncation of GluR6 reduced the efficiency of subunit assembly into hetero-oligomeric receptors, we coexpressed R6-850stop with a myc-tagged KA2 subunit and recorded currents from heteromeric receptors in HEK 293 cells (data not shown). Recombinant GluR6/KA2 receptors have a significantly faster desensitization rate than homomeric GluR6 receptors (Dingledine et al., 1999), and therefore heteromeric receptor complexes are readily discernible by their characteristic current kinetics. We determined that R6-850stop mutants formed heteromeric complexes with myc-KA2 subunits that were functional and gated rapidly desensitizing currents (peak amplitude $0.38 \pm 0.19 \mathrm{nA}, \tau_{\text {des }}=$ $1.4 \pm 0.2 \mathrm{msec}, n=4$; compared with GFP-GluR6 $\tau_{\text {des }}$ of $4.5 \pm$ $0.2 \mathrm{msec}, n=30$ ). In addition, anti-myc immunoreactivity was detected on the surface of cells transfected with a combination of R6-850stop and myc-KA2 but not in cells transfected with mycKA2 alone (Fig. $2 F$ ), consistent with the efficient formation and surface expression of $\mathrm{R} 6-850$ stop/KA2 receptors. We conclude from these data that dramatic reductions in subunit expression or oligomerization do not underlie the differential surface localization of the truncated subunits.

These data suggest that the 13 amino acids between residues 868 and 880 in the GluR6 C terminus are determinants of receptor trafficking. This region of the subunit is enriched in basic amino acids, has a putative phosphorylation consensus for protein kinase $\mathrm{C}$ and cAMP-dependent protein kinase at serine 868 (Falquet et al., 2002), has a palmitoylated cysteine at residue 871

in COS-7 cells. Red (surface receptors) and green (GFP fluorescence) channels were overlaid. R6-850stop receptors were expressed only weakly on the cell surface and exhibited a more punctate and perinuclear total GFP fluorescence distribution. $\mathrm{R6}-868$ stop receptors expressed on the plasma membrane, but at a much lower level of GFP-GluR6. Intensity of anti-GFP staining from cells expressing R6 - 880stop receptors was similar to that of GFP-GluR6; however, the surface distribution appeared to be more clustered rather than evenly spread over the cell surfaces (compare with A). D, Colocalization of GFP-GluR6 and R6-850stop with markers for endoplasmic reticulum (PDI) and cis- and medial-Golgi compartments (giantin). GFP-GluR6 colocalizes with both PDI and giantin, whereas R6 - 850stop partially colocalizes with PDI and does not overlap with giantin. Red and green channels were overlaid in these confocal images, which are single optical slices with a thickness of $0.38-0.40 \mu \mathrm{m}$. 

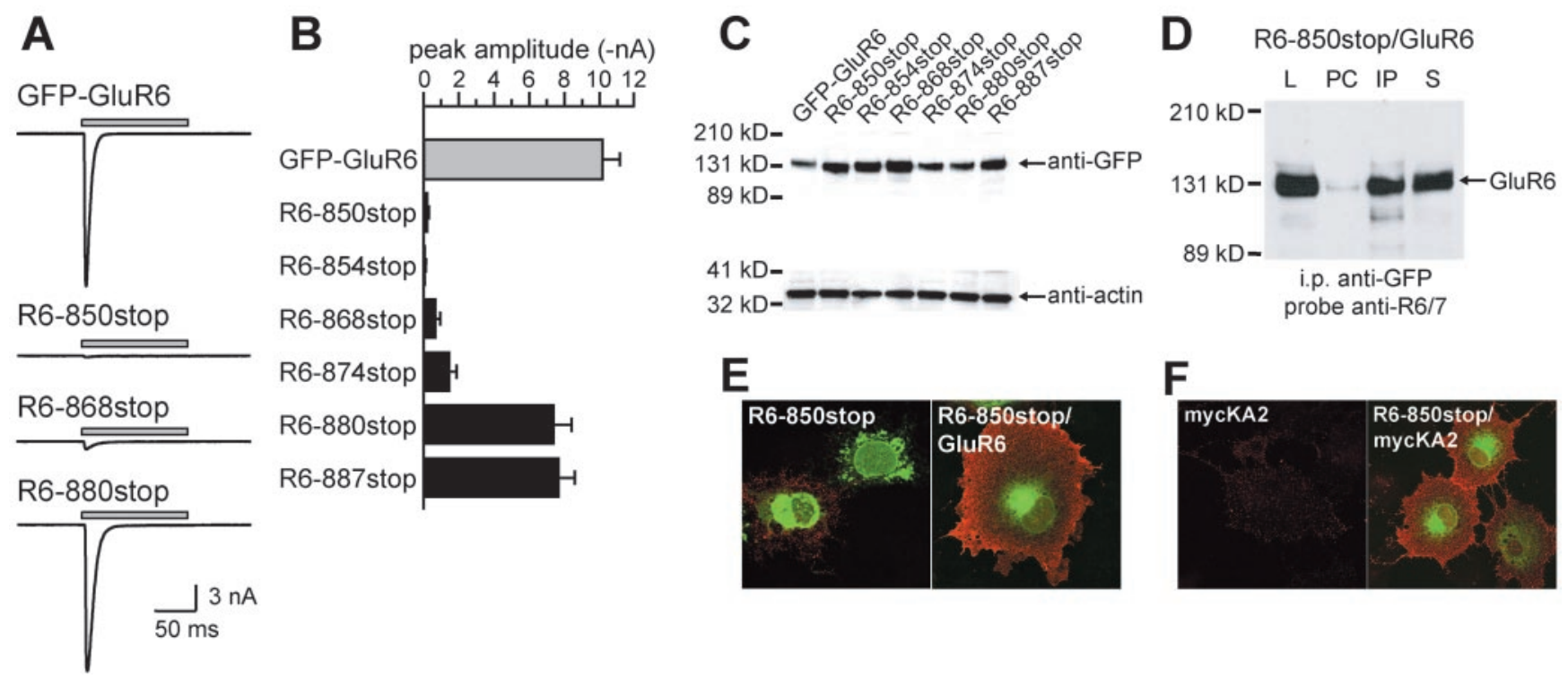

Figure 2. The reduction in surface immunofluorescence is caused by impaired trafficking of functional receptors to the cell surface. $A$, Truncated receptors show a reduction in functional expression when expressed in HEK 293 at levels comparable with that in the qualitative immunofluorescent study. Representative currents are shown arising from glutamate application (gray bar; $10 \mathrm{~mm}, 100 \mathrm{msec}$ ) to receptor-expressing cells. Currents are shown on the same scale for the sake of comparison. Whole-cell recordings were made at a holding potential of $-70 \mathrm{mV}$. $B$, Mean amplitudes of GFP-GluR6 and serial truncation mutants (mean \pm SEM). Three levels of expression were observed, corresponding to the qualitative measure of surface immunofluorescence in the previous experiment. C, Reduced surface expression did not result from decreased total expression of truncated GluR6 subunits. Equivalent amounts of protein isolated from transfected COS-7 cell lysates were loaded on SDS-PAGE gels. Western blots for GFP and actin were performed in parallel from the same SDS-PAGE gels. D, R6 - 850stop subunits form hetero-0ligomers with GluR6 subunits. After coexpression R6-850stop (with a GFP tag) and GluR6 (without GFP) in COS-7 cells, lysates were incubated with protein A-conjugated beads (pre-clear), followed by anti-GFP antibody bound to protein A-conjugated beads (to precipitate R6 - 850stop proteins). Western blots were performed with samples of the cell lysate (L), protein eluted from the pre-clear beads (PC), protein eluted from the immunoprecipitate beads (IP), and supernatant after immunoprecipitate (S) using anti-GluR6/7 antibody, which was raised against the (-terminal of GluR6 and consequently does not recognize the truncated R6 - 850stop subunit. The presence of the GluR6 subunit in the immunoprecipitate indicates that R6 - 850stop and GluR6 subunits coassembled into hetero-oligomeric receptors. E, Coexpression with GluR6 subunit significantly increases surface levels of R6 - 850stop protein. GluR6 and R6 - 850stop were coexpressed in COS-7 cells (at a ratio of 3:1), and anti-GFP immunoreactivity was detected in nonpermeabilized cells, yielding qualitative measures of surface expression of R6 - 850stop subunits. An image from cells expressing only R6-850stop is shown for comparison; two cells are visible, one of which weakly expresses the truncated receptor on the cell surface. F, R6 - 850stop subunits coassemble with KA2 subunits. Coexpression of a myc-tagged KA2 subunit with R6-850stop increases membrane expression of the KA2subunit to detectable levels (nonpermeabilized COS-7 cells were stained with anti-myc antibodies; the homomeric myc-KA2 is shown for comparison).

(Pickering et al., 1995), and contains approximately half of a region with a weak homology to an $\mathrm{SH} 3$ protein interaction domain (Yaffe et al., 2001) (low-stringency motif scan) (Fig. 3A). The functional significance of these potential modification or interaction sites is unknown. Serial truncations were made in the GFP-GluR6 subunit at each amino acid between 868 and 880, the two boundary residues for alterations in surface expression and function. Analysis of the peak amplitudes of glutamate-evoked currents from kainate receptors formed from this new set of truncated subunits are shown in the histogram in Figure $3 B$ (left). Representative currents from a trafficking-compromised receptor, R6-874stop, and a wild-type-like receptor, R6-878stop, are shown in Figure $3 B$, right side. Truncation of GluR6 subunits at each residue from $S 868$ to K876 significantly reduced current amplitudes to $<20 \%$ of GFP-GluR6 current amplitudes, with the exception of R6-875stop, which was $25 \%$ of the mean control amplitude (in nanoamperes; R6-868stop, $0.72 \pm 0.24$; R6869stop, $1.15 \pm 0.34$; R6-870stop, $0.75 \pm 0.23$; R6-871stop, $0.88 \pm 0.29$; R6-872stop, $1.03 \pm 0.38$; R6-873stop, $0.52 \pm 0.17$; R6-875stop, $2.25 \pm 0.62$, R6-876stop: $0.27 \pm 0.09 ; n=7-13$; all $p<0.05$ compared with GFP-GluR6). Receptor R6-877stop had mean current amplitudes intermediate to those of GFPGluR6 receptors and the shorter truncation mutants (5.74 \pm 0.69 $\mathrm{nA} ; n=24 ; p<0.05$ compared with R6-868stop to R6-876stop and GFP-GluR6), whereas R6-878stop, R6-879stop, and R6880stop had mean amplitudes only slightly smaller than that of control GFP-GluR6 (R6-878stop, $7.94 \pm 1.00 \mathrm{nA}, n=9$; R6- 879stop, $7.43 \pm 0.74 \mathrm{nA}, n=23$; R6-880stop, $7.43 \pm 0.98 \mathrm{nA}$; $n=18$ ). These serial truncations identified the region surrounding lysine 876 as particularly critical for functional expression of GluR6 receptors on the plasma membrane.

We also analyzed the desensitization kinetics of currents evoked by glutamate from truncated receptors. Each current decay was best-fit with either one or two exponential decay curves, and the predominant component was used in calculations for the histogram in Figure 3C. GFP-GluR6 receptors desensitize with a time course of $4.5 \pm 0.2 \mathrm{msec}$ during the $100 \mathrm{msec}$ application $(n=30)$. Approximately half of our truncated subunits (R6868stop to R6-874stop and R6-876stop) formed receptors with a slowed time course of desensitization as compared with wildtype receptors (R6-868stop, $7.8 \pm 0.4 \mathrm{msec}$; R6-869stop, $6.6 \pm$ 0.9 msec; R6-870stop, $5.6 \pm 0.6 \mathrm{msec}$; R6-871stop, $6.7 \pm 0.6$ msec; R6-872stop, $7.3 \pm 0.8 \mathrm{msec}$; 6 -873stop, $7.5 \pm 0.5 \mathrm{msec}$; R6-874stop, $5.8 \pm 0.7 \mathrm{msec}$; R6-876stop, $6.3 \pm 0.8 \mathrm{msec} ; n=$ 7-13). In contrast, desensitization rates for R6-875stop and R6877stop to R6-880stop receptors were not different from GFPGluR6 receptors (R6-877stop, $4.1 \pm 0.2 \mathrm{msec}$; R6-878stop, $4.3 \pm 0.2$ msec; R6-879stop, $4.9 \pm 0.3$ msec; R6-880stop, $4.2 \pm$ $0.1 \mathrm{msec} ; p>0.05)$. Representative currents from GFP-GluR6 and R6-873stop are shown in Figure 3C, right side; in this example the peak of the small R6-973stop current was normalized to the peak of the GFP-GluR6 current. Although there was a general correlation between those receptors that had reduced expression and slowed desensitization, one truncation mutant, R6-875stop, 
A
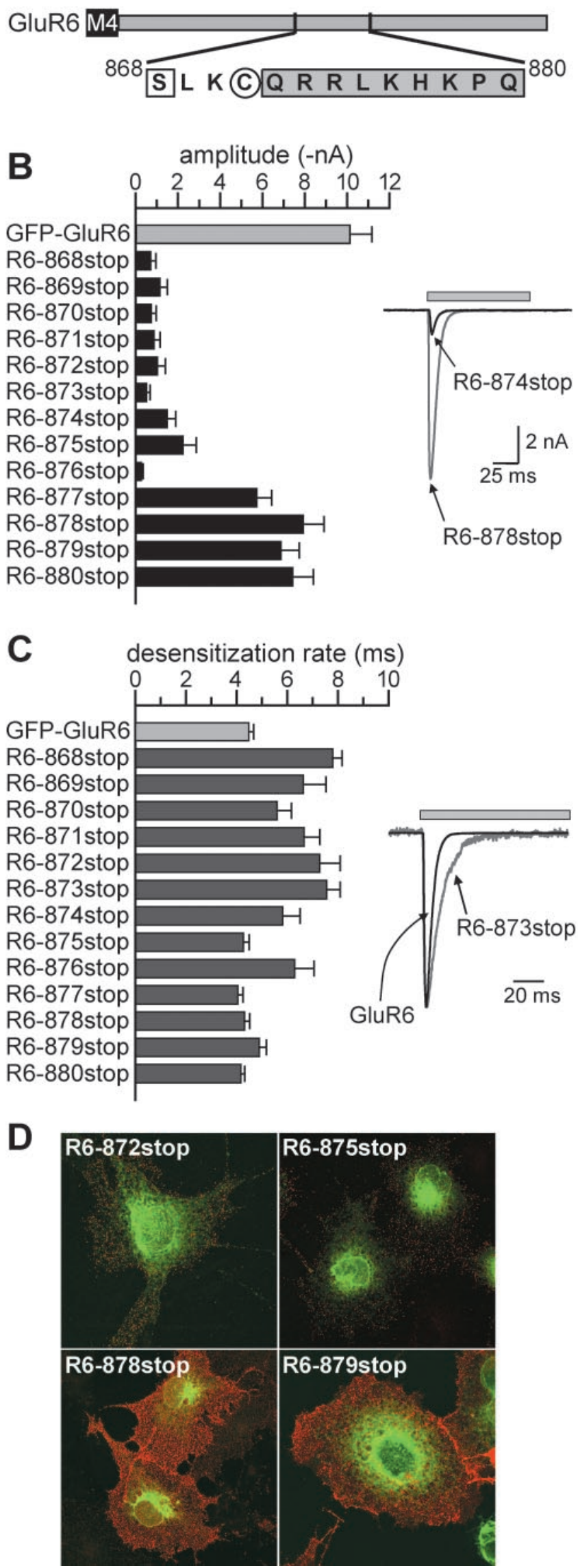

was a notable exception with a normal desensitization rate $(4.3 \pm$ $0.2 \mathrm{msec})$ but a reduced peak current $(2.2 \pm 0.6 \mathrm{nA} ; n=12)$. The significance of these changes in desensitization rates is unclear but generally suggests that interactions with other proteins or modification of residues in the $\mathrm{C}$ terminal influence kinetic behavior of kainate receptors, as has been shown previously (Traynelis and Wahl, 1997; Garcia et al., 1998; Swanson and Heinemann, 1998).

Immunofluorescent analysis of surface expression of the serially truncated subunits correlated well with the physiological results. Representative images of four mutants, R6-872stop, R6875stop, R6-878stop, and R6-879stop, are shown in Figure 3D. Those receptors that gated only small currents were expressed lightly on the surface of COS-7 cells (e.g., R6-872stop and R6875stop) compared with the receptors with longer C-terminal domains that gated large currents (e.g., R6-878stop and R6879 stop). As with other truncation mutants of the GluR6 subunit, punctuate surface staining suggested that the receptors were clustered rather than distributed smoothly across the plasma membrane. The predominant intracellular localization to ER compartments did not appear altered in these truncated subunits. Thus, the physiological and immunolocalization analysis of the serial truncation mutants suggested that residues near lysine 876 were critical determinants of trafficking to the cell surface.

We next tested the importance of individual subsets of amino acids within the C-terminal trafficking domain using a mutational scanning approach in which one or more residues were changed to alanines. Site-directed mutagenesis yielded new GFPGluR6 mutants with alanine replacement of individual residues from leucine 869 to proline 879 (Fig. $4 A$, single alanine mutants). The mean amplitudes of peak glutamate currents are shown in the histogram in Figure $4 B$. We found that individual mutation of two residues, C871 or R873, reduced the mean current amplitude by $\sim 30 \%$ as compared with GFP-GluR6 receptors (GFPGluR6: $10.15 \pm 1.01 \mathrm{nA}, n=25$; R6(871A): $7.06 \pm 1.11 \mathrm{nA}, n=$ 22; R6(873A): $6.72 \pm 0.60 \mathrm{nA}, n=20 ; p<0.05)$. Amplitudes of all other single-site mutants were indistinguishable from GFP-

Figure 3. Serial truncation of GFP-GluR6 in the region of interest between residues 868 and 880 further localizes a putative trafficking determinant. $A$, The diagram illustrates the amino acid sequences between $\$ 868$ and Q880. $\$ 868$ (square) is a predicted consensus site for phosphorylation by protein kinase C. C871 (circle) was shown previously to be modified by palmitoylation (Pickering et al., 1995). The shaded region was identified as having weak homology with an SH3 protein interaction domain (Yaffe et al., 2001). GFP-GluR6 receptors truncated at each of the sites shown were generated by site-directed mutagenesis. $B$, Left, Mean current amplitudes from GFP-GluR6 receptors truncated between residues 868 and 880 . Truncation at all sites between 5868 and K876 significantly reduced functional expression of GluR6 receptors. Right, Representative currents evoked from HEK 293 cells expressing R6 - 878stop, a truncated receptor with currents similar in amplitude to GFP-GluR6, and R6 - 874stop, which had much smaller currents than wild-type receptors. Glutamate (10 mM, gray bar) was applied for 100 msec. The holding potential was $-70 \mathrm{mV}$ for all recordings. C, Left, Mean desensitization rates from GFP-GluR6 receptors truncated between residues 868 and 880 . Truncation at all sites between $S 868$ and K876, except L875, slowed desensitization of GluR6 receptors in response to glutamate application. Desensitization rates were best-fitted with one or two exponential decay functions, and the predominant component was used to calculate mean values. Right, Representative currents from HEK 293 cells expressing GFP-GluR6 and R6 - 873stop, which had a significantly slower time course of desensitization. The latter is normalized to the peak amplitude of the GFP-GluR6 current to compare the desensitization rates. D, Representative confocal images from anti-GFP surface-stained cells expressing GluR6 truncation mutants. Red and green channels were overlaid. R6 - 872stop and R6 - 875stop receptors were only weakly detected on the surface of $\operatorname{COS}-7$ cells; the total fluorescence (green) was consistent with retention in the ER. In contrast, R6 - 878stop and R6 - 879stop receptors were strongly expressed on the cell surface (red staining), consistent with the current recordings shown in $B$. 

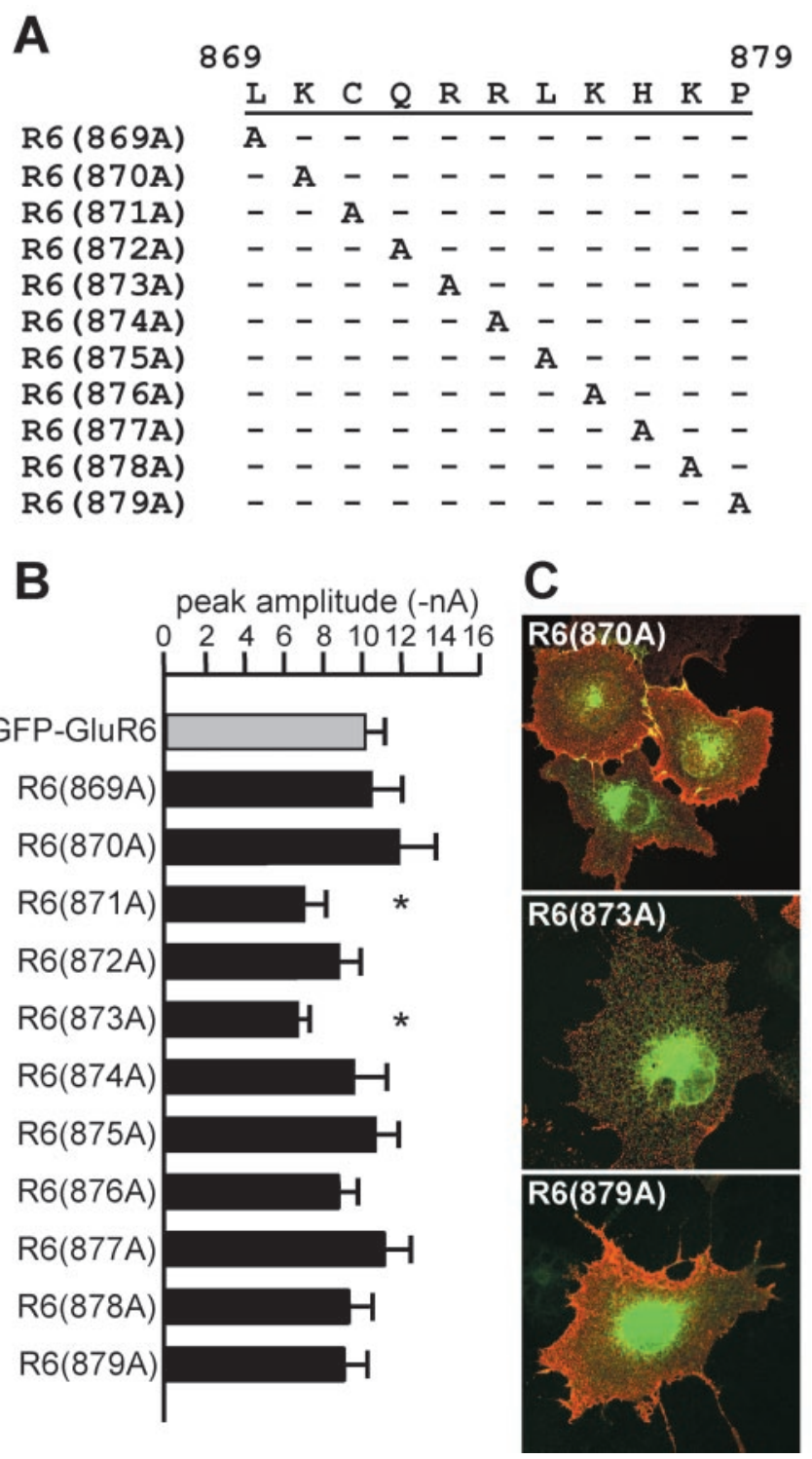

Figure 4. Alanine scanning mutagenesis of the putative forward trafficking domain in GluR6 between residues 869 and 879 identifies two weak determinants. $A$, Single-site mutagenesis of the GFP-GluR6 subunit produced the indicated alanine substitutions. $B$, Mean current amplitudes of alanine mutants were similar to that of GFP-GluR6 receptors with the exception of R6 $(871 \mathrm{~A})$ and R6(873A), which had mean amplitudes $20 \%$ smaller than GFP-GluR6 ( ${ }^{*}$ significant at $p<0.05)$. C, Representative surface immunostaining for three single alanine GFPGluR6 mutants. Red and green channels were overlaid. Levels of surface expression were not distinguishable between alanine mutants in this assay, although plasma membrane levels of $\mathrm{R} 6(871 \mathrm{~A})$ and R6(873A) were qualitatively lower in some cells compared with GFP-GluR6.

GluR6 receptors. Desensitization rates for single alanine mutants were also similar to GFP-GluR6 receptors (data not shown). Immunofluorescent imaging of surface and total alanine mutant receptors did not reveal gross differences in their distribution, although in a number of cells expressing R6(871A) and R6(873A) the intensity of surface staining for GFP was qualitatively lower compared with cells expressing other receptors [Fig. 4C, R6(870A), R6(873A), and R6(879A)]. Thus, alanine scanning of amino acids in the $869-880$ region revealed two residues, C871 and $\mathrm{R} 873$, that play a role in the plasma membrane expression of homomeric GluR6 receptors.

To further identify important residues distributed across the region between $\mathrm{C} 871$ and $\mathrm{H} 877$, we generated additional multiple-site alanine mutants as illustrated in Figure 5A. Representative currents from multiple site mutants are shown in Figure $5 B$, mean amplitudes are given in the histogram in Figure $5 C$, and representative immunofluorescent images are shown in Figure 5D. In our first multiple-site mutant, R6(871-877A), all seven residues were replaced with alanines. This mutant subunit had a dramatically altered receptor cell surface expression; R6(871$877 \mathrm{~A})$ current amplitudes were only $1 \%$ of that of GFP-GluR6 receptors [R6(871-877A): $0.11 \pm 0.03 \mathrm{nA} n=7]$, and surface immunolabeling was very weak and punctate only in a subset of transfected cells (Fig. 5D). GluR6 mutants with alanines substituted at residues $873-877$ or with these five residues deleted from the $\mathrm{C}$ terminus also exhibited markedly reduced surface expression; current amplitudes from R6(873-877A) and R6del873-877 receptors were on average $80 \%$ lower than wild type [R6(873877A): $2.0 \pm 0.8 \mathrm{nA}, n=17$; R6del873-877: $2.5 \pm 0.3 \mathrm{nA}, n=7)$. Surface labeling of the receptors with anti-GFP antisera was variable: some transfected cells had strong expression, whereas in others surface was essentially absent [the variable level of surface expression (red) is evident in Fig. 5D].

The importance of subsets of amino acids within the seven residue domain was analyzed with the more restricted alanine substitution mutants R6(871-873A), R6(874-875A), and R6(876-877A). R6(871-873A) receptors were poorly expressed on the cell surface (mean current amplitude of $1.02 \pm 0.23 \mathrm{nA}$, $n=10$; a $90 \%$ reduction from GFP-GluR6). To determine whether a particular pair of amino acids in this set of three residues was critical for trafficking, we analyzed three additional double mutants: R6(871A,873A), R6(871-872A), and R6(872$873 \mathrm{~A})$. Currents from these mutant receptors were not attenuated to the same degree as the triple mutant; only R6(872-873) was significantly reduced (by $\sim 50 \%$ ) compared with GFPGluR6 [R6(871A,873A): $8.01 \pm 0.61 \mathrm{nA}, n=25$; R6(871-872A): $9.95 \pm 1.40 \mathrm{nA}, n=7$; R6(872-873A): $5.18 \pm 1.29, n=7 ; p<$ 0.05 for the latter mutant only]. R6(874-875A) and R6(876$877 \mathrm{~A})$ receptors formed functional receptors that gave current amplitudes that were significantly reduced compared with GFPGluR6 receptors but not to the same profound degree as observed for R6(871-873A) [R6(874-875A): $5.46 \pm 0.83 \mathrm{nA}, n=14$; R6(876-877A): $6.60 \pm 1.06 \mathrm{nA}, n=20 ; p<0.05$ ].

R6(871-877A) receptors were confined primarily to ER compartments. GFP fluorescence from the mutant receptor extensively colocalized with immunoreactivity for the ER marker PDI but not with the cis- and medial-Golgi marker giantin, suggesting that the mutant receptor was unable to traffic forward from the ER (or was efficiently retrieved from ER-Golgi intermediate compartments) (Fig. 5E). In addition, R6(871-877A) receptor protein was sensitive to digestion by endo $\mathrm{H}$, an endoglycosidase that cleaves sugar residues from immature glycoproteins that do not mature through the Golgi stacks. In contrast, GFP-GluR6 protein was partially resistant to endo $\mathrm{H}$ digestion (data not shown). R6(871-877A) receptor protein was expressed at levels comparable with GFP-GluR6 in Western blots (data not shown). These data suggest that residues 871-877, and particularly C871, Q872, and R873, comprise a trafficking motif critical for early steps in the biosynthetic pathway.

We tested whether residues $871-873$ acted as a critical C-terminal trafficking determinant when transferred to a glutamate receptor subunit that normally does not express on the plasma membrane. A chimeric KA2 subunit containing an $\mathrm{N}$-terminal myc tag and the C-terminal domain from GluR6 (myc-KA2 $\Delta$ GluR6) was shown previously to traffic efficiently to the cell surface, in contrast to wild-type KA2 subunits, which are 
retained in the ER (Ren et al., 2003) (Fig. $6 A$ ). We introduced two multiple alanine substitutions into myc-KA2 $\Delta$ R6 that in the GluR6 subunit produce distinct levels of surface expression, 871-873A and 874$875 \mathrm{~A}$, and tested cell surface expression using anti-myc immunofluorescence. MycKA2 $\Delta$ R6(871-873A) receptors were expressed only weakly on the cell surface, whereas myc-KA2 $\Delta$ R6 $(874-875 \mathrm{~A})$ receptors were expressed at levels comparable with the parent chimeric protein (Fig. 6A, left). Quantitation of surface expression of these receptors was performed using an ELISA in which surface expressed receptors were detected by generation of a colorimetric product by antibody-linked enzyme. As shown in Figure 6A, the color reaction from cells transfected with myc-KA2 receptors was only slightly denser than nontransfected cells, whereas myc-KA2 $\Delta$ R6 receptors generated a robust color reaction significantly larger than myc-KA2 receptors (5.5-fold increase; $n=3$ experiments with five replicates per experiment). In agreement with the immunofluorescent results, introduction of the 871-873A mutations reduced color density close to that of myc-KA2 (1.9-fold increased surface expression). Myc-KA2 $\Delta$ R6(874$875 \mathrm{~A}$ ) receptors gave an intermediate level of color density (3.8-fold increase compared with myc-KA $\Delta$ R6). Thus, these results were qualitatively similar to those with GFPGluR6 and further demonstrate that the 871-873 region functions as a critical element of the forward trafficking signal.

Although our results with the truncated and alanine-substituted receptors strongly suggested that the 871-877 domain was primarily a trafficking signal rather than a determinant of oligomerization, we could not entirely rule out the possibility that mutation of this region impacted the efficiency of assembly and thereby reduced surface expression of functional receptors. To obviate the complications associated with assembly of the subunit proteins, we examined the role of residues $871-877$ in trafficking of the monomeric protein Tac, a widely used construct that consists of the extracellular and first membrane domain of the interleukin-2 receptor (Fig. 6B). A chimeric Tac protein with a fused GluR6 C-terminal tail was readily detected on the surface of transfected COS-7 cells with anti-Tac antibodies (Fig. 6B, left). Alanine mutation of CQR (equivalent to 871-873) in the Tac-R6 construct slightly reduced surface expression in immunofluorescent assays, whereas mutation of all seven residues corresponding to 871-877 significantly reduced surface levels of Tac-R6 protein. Cell ELISA assays with Tac-R6, Tac-R6(871-873A), and Tac-R6(871-877A) supported these observations; surface expression of Tac-R6(871-8732A) was $21.1 \pm 2.4 \%$ lower and Tac-R6(871-877A) was $73.3 \pm$ $11.6 \%$ lower than Tac-R6 in parallel assays (values normalized to
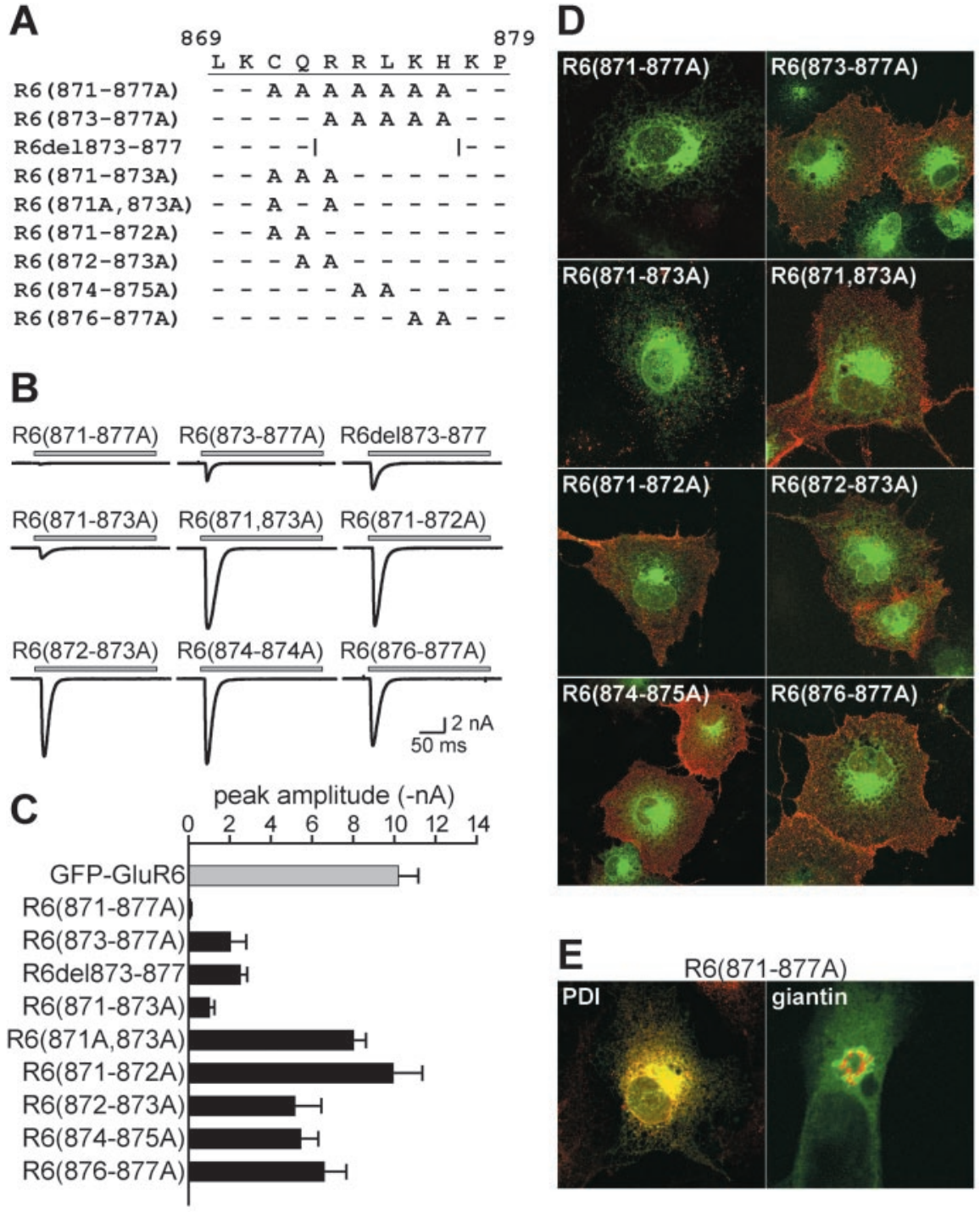

Figure 5. Multiple alanine mutation of the forward trafficking determinant in the GluR6 C-terminal tail. $A$, Multiple alanine substitutions were generated as indicated in GFP-GluR6 subunits. A receptor with five residues deleted (R6-del873-877) was whole-cell recording from receptor-expressing HEK 293 cells. The recordings are shown on the same scale for comparison. Current amplitudes from R6(871-877A) receptors were $<10 \%$ of those from GFP-GluR6 receptors. C, Mean current amplitudes for the GluR6 receptors, with the exception of R6(871-872A) receptors. D, Representative projection images from GFP-GluR6 mutant receptors containing multiple alanine substitutions expressed in COS-7 cells. Red and green channels were overlaid. Qualitative receptors were detected on the cell surface, but the total fluorescence remained reticular. $E, R 6(871-877 \mathrm{~A})$ receptors colocalize well with the ER marker PDI but not with the Golgi marker giantin. PDI and giantin are in red; total GFP fluorescence from the receptor is green; overlap is yellow. Images are single confocal sections of $0.38-0.39 \mu \mathrm{m}$ thickness.

mean absorbances for Tac-R6 for each experiment, $n=6$ and 3 experiments, respectively; $p<0.05$ for both mutants) (Fig. $6 B$, right). Western blots confirmed that expression levels of the proteins were equivalent in these assays. These data demonstrate that the CQRRLKH motif acts as a trafficking determinant in the context of a monomeric fusion protein with only the cytoplasmic tail from the GluR6 subunit.

It is also possible that mutation of the CQRRLKH domain resulted in aberrant folding of the subunit proteins and thereby caused retention and increased degradation in the ER. We tested this possibility by first determining whether R6-850stop and R6(871-877A) receptors, which are confined predominantly to 
A

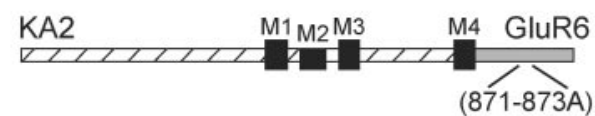

$(874-875 A)$
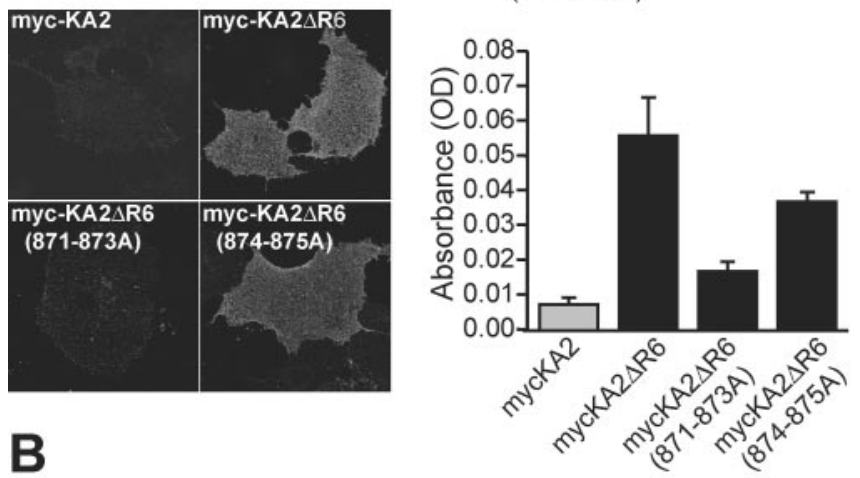

B

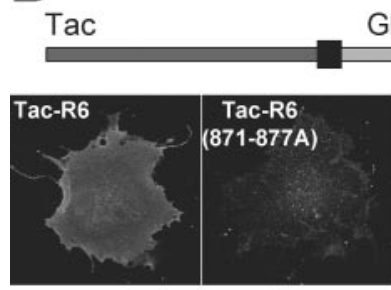

C

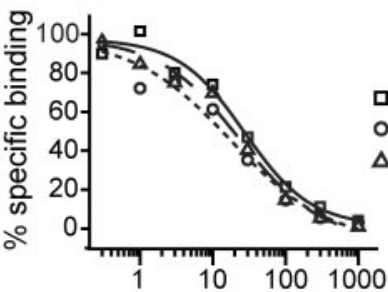

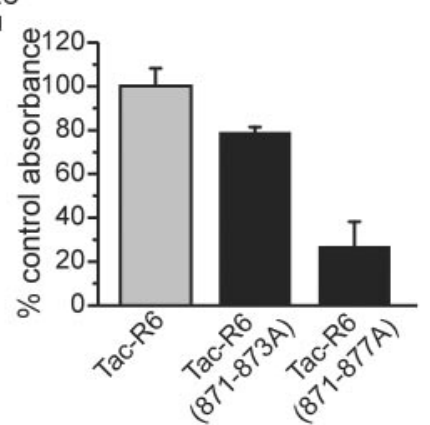

口 GFP-GluR6

- R6(871-877A)
$\Delta$ R6-850stop
[SYM 2081] (nM)
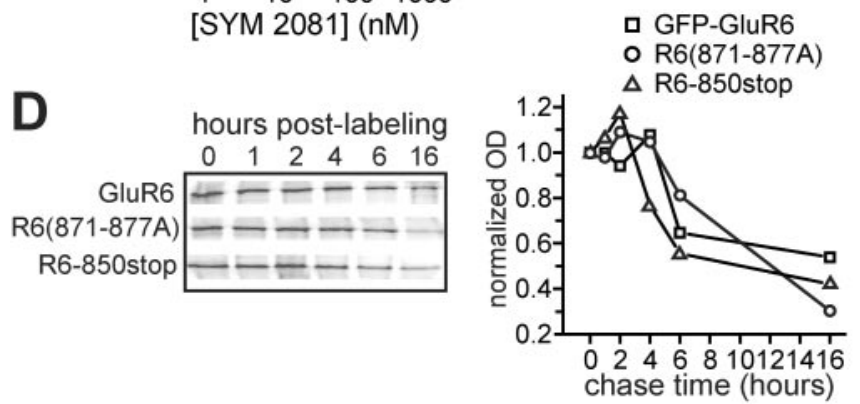

Figure 6. The GluR6 forward trafficking determinant controls surface expression of chimeric KA2 subunits and monomeric Tac-R6 constructs. A, Surface expression of chimeric KA2 subunits containing the GluR6 C terminus is controlled by the GluR6 trafficking determinant. Top, Diagram illustrating the myc-KA2 $\Delta R 6$ chimeric subunit, in which the C-terminal tail of the GluR6 subunit (gray) replaced that of KA2 (hatched). Multiple alanine mutations were made to mycKA2 $\triangle R 6$ as indicated. Left, Representative confocal images after detection of surface receptors using anti-myc primary antibodies on COS-7 cells expressing myc-KA2, myc-KA2 $\triangle R 6$, myc-KA2 $\Delta R 6(871-873 \mathrm{~A})$, and myc-KA2 $\Delta R 6(874-875 \mathrm{~A})$. Myc-KA2 was not expressed on the plasma membrane to an appreciable degree, whereas cells with myc-KA2 $\Delta R 6$ receptors showed clear surface expression. Mutations in the trafficking domain reduced surface expression of the chimera to approximately the same degree observed in GFP-GluR6 alanine mutants. Right, Quantitative measurement of surface expression of myc-tagged constructs demonstrates that mutations in the GluR6 trafficking domain reduced forward trafficking of chimeric myc$K A 2 \Delta R 6$ subunits. Cell ELISAs were performed for detection of an extracellular myc antigen in COS-7 cells expressing myc-KA2, myc-KA2 $\Delta R 6$, myc-KA2 $\Delta R 6(871-873 A)$, and myc$K A 2 \Delta R 6(874-875 A)$. Absolute optical density in three separate experiments (5 replicates per experiment; mean background absorbance subtracted) was averaged and is shown in the graph (mean \pm SEM). Reactions were developed for $\sim 2 \mathrm{hr}$ in each case. $B$, The $871-877$ domain is a the ER, retained ligand-binding affinities similar to that of GFPGluR6 receptors (Fig. 6C). In homologous competition displacement assays, the kainate receptor agonist $(2 S, 4 R)$-4-methylglutamate (SYM 2081) displaced radiolabeled [ $\left.{ }^{3} \mathrm{H}\right]$ SYM 2081 (10 nM) with $\mathrm{IC}_{50}$ values of $25.9 \pm 1.4,13.8 \pm 1.0$, and $17.5 \pm 3.4 \mathrm{~nm}$ for GFP-GluR6, R6(871-877A), and R6-850stop receptors, respectively ( $n=3$ assays for each receptor type); $B_{\max }$ values were also comparable at $1.8 \pm 0.2,2.1 \pm 0.2$, and $2.0 \pm 0.2 \mathrm{pmol} / \mathrm{mg}$. These binding data demonstrate that receptors retained in the ER are not grossly misfolded in a way that eliminates their binding affinity for this ligand. Although the similar $B_{\max }$ values suggest that R6(871877A) and R6-850stop are not degraded rapidly as a result of putative misfolding, we tested this possibility further in pulse-chase experiments. The stability of proteins in the ER was measured by $\left[{ }^{35} \mathrm{~S}\right]$ labeling of newly synthesized proteins for $30 \mathrm{~min}$ in the presence of brefeldin A, which blocks transport from the ER to the Golgi, and chasing for various times afterward in the continued presence of brefeldin A (Fig. 6D). At the indicated time points, cells were lysed and the receptors were immunoprecipitated with anti-GFP antibody before the proteins were resolved using SDS-PAGE. We found that GFP-GluR6, R6(871-877A), and R6-850stop receptors were stable in the ER for up to $4 \mathrm{hr}$ before turning over at relatively similar rates. These data demonstrate that mutant GluR6 receptor subunits do not undergo increased degradation rates in the ER as a result of elimination of either the CQRRLKH domain or most of the cytoplasmic tail. Thus, misfolding is unlikely to account for the retention of GluR6 receptors lacking the CQRRLKH domain.

In our final set of experiments, we determined whether the GluR6 871-877 domain that controls trafficking in heterologous expression systems served an equivalent role in neurons. Hippocampal neurons grown under standard culture conditions were transfected with GFP-GluR6, R6-850stop, R6(871-873A), R6(873-877A), R6del873-877, or R6(871-877A) receptor cDNAs. Nonpermeabilized neurons were probed for extracellular anti-GFP immunoreactivity to measure surface expression of the recombinant GluR6 receptors (Fig. 7A). Total GFP fluorescence in transfected neurons was distributed throughout the somatodendritic compartment. GFP-GluR6 and R6(873-877A) receptors were also distributed on the plasma membrane of the somatodendritic compartment, in contrast to R6-850stop, R6(871-873A), R6del873-877,

forward trafficking signal in a monomeric Tac-R6 construct. Top, The GluR6 C-terminal domain (light gray) was fused to the extracellular and first transmembrane domains of the interleukin-2 receptor (Tac, dark gray). Left, The monomeric protein was readily detected on the plasma membrane of nonpermeabilized cells using anti-Tac antibody; in contrast, surface expression of Tac-R6(871-877A) was significantly lower. Right, Quantitative measurement of surface expression of Tac-R6, Tac-R6(871-873A), and Tac-R6(871-877A) demonstrates that mutations in the GluR6 trafficking domain reduced forward trafficking of Tac-R6 subunits. Cell ELISAs were performed for detection of extracellular Tac immunoreactivity in $\mathrm{COS}-7$ cells. Normalized optical density in three separate experiments ( $4-8$ replicates per experiment; mean background absorbance subtracted) was averaged and is shown in the graph (mean \pm SEM). Reactions were developed for $\sim 30$ min in each case. C, GFP-GluR6, R6(871-871A), and R6-850stop have equivalent binding affinities. Homologous displacement of [ $\left.{ }^{3} \mathrm{H}\right] \mathrm{SYM} 2081$ by unlabeled SYM 2081 was assayed for the three receptors (GFP-GluR6: squares, solid line; R6(871-877A): circles, dotted line; R6-850stop: triangles, dashed line); representative data fitted to logistic functions are shown. Mean $\mathrm{IC}_{50}$ values were $25.9 \pm 1.4,13.8 \pm 1.0$, and $17.5 \pm 3.4 \mathrm{~nm}$ for GFP-GluR6, R6(871-877A), and R6-850stop receptors, respectively ( $n=3$ displacement assays for each receptor type). D, Pulse-chase assays demonstrate that rates of degradation in the ER are equivalent for GFP-GluR6, R6 (871-877A), and R6 - 850stop receptors. Transfected HEK cells were labeled metabolically for $30 \mathrm{~min}$ before chasing for the times indicated in the figure. Receptors were isolated by immunoprecipitation with anti-GFP antibody and run on SDS-PAGE gels. Phosphorimager exposures are shown on the left; quantified signals were normalized to time point zero and plotted as the normalized optical density against the time of chase to yield the graph shown on the right. 
and $\mathrm{R} 6(871-877 \mathrm{~A})$ receptors, which were predominantly excluded from the surface of the neurons. Quantitation of anti-GFP staining intensity by measuring ratios of red to green fluorescence demonstrated that surface levels of R6-850stop and R6(871$873 \mathrm{~A}$ ) receptors were reduced by $\sim 70 \%$ and R6del873-877 and R6(871-877A) receptors were reduced by $\sim 90 \%$ compared with GFP-GluR6 (Fig. 7B). In contrast, the fivealanine mutant R6(873-877A) was reduced by only $20 \%$ compared with GFP-GluR6 ( $n=8-10$ cells analyzed for each group; wild-type mean red/green ratio of $0.59 \pm$ $0.03)$. These results demonstrate that the 871-877 domain functions as a trafficking determinant for surface targeting of GluR6 receptors in cultured neurons as well as in heterologous expression systems.

\section{Discussion}

In this study, we defined a minimal C-terminal motif necessary for surface expression of homomeric GluR6 kainate receptors. Serial truncation of the cytoplasmic tail of the GluR6 subunit, followed by alanine scanning mutagenesis, revealed a trafficking determinant between residues 871 and 877 (CQRRLKH) composed predominantly of basic amino acids. Alanine substitution of these seven amino acids profoundly reduced surface expression of GluR6 kainate receptors. The first three amino acids were particularly critical components; alanine substitution of residues $871-873$ resulted in $\sim 90 \%$ reduction in the functional expression of homomeric GluR6 receptors. We verified that the decreased surface expression was not caused by poor expression of the subunits, impeded assembly of homo-oligomeric or hetero-oligomeric receptor complexes, altered binding properties, or increased rates of degradation of mutant receptors. The CQRRLKH domain controlled surface expression of a monomeric Tac-R6 protein, establishing it as a bona fide forward trafficking signal. This motif is the first such determinant characterized for kainate receptor subunits.

Our initial analysis of truncated GluR6 subunits suggested that two distinct trafficking determinants existed in the C-terminal tails. The two shortest truncation mutants, R6-850stop and R6-854stop, had glutamate-evoked currents only $\sim 1 \%$ of that from GFP-GluR6 receptors and a punctate intracellular localization in transfected COS-7 cells (Figs. $1 C, D, 2 F$ ). The areas of prominent intracellular fluorescence partially colocalized with markers for the ER but were not colocalized with cis- or medial-Golgi compartments (Fig. $1 D$ ). In contrast, somewhat longer truncation mutants (R6-868stop and R6-874stop) that also showed reduced surface expression predominantly exhibited reticular fluorescence consistent with ER localization. Our results demonstrate that complete or partial
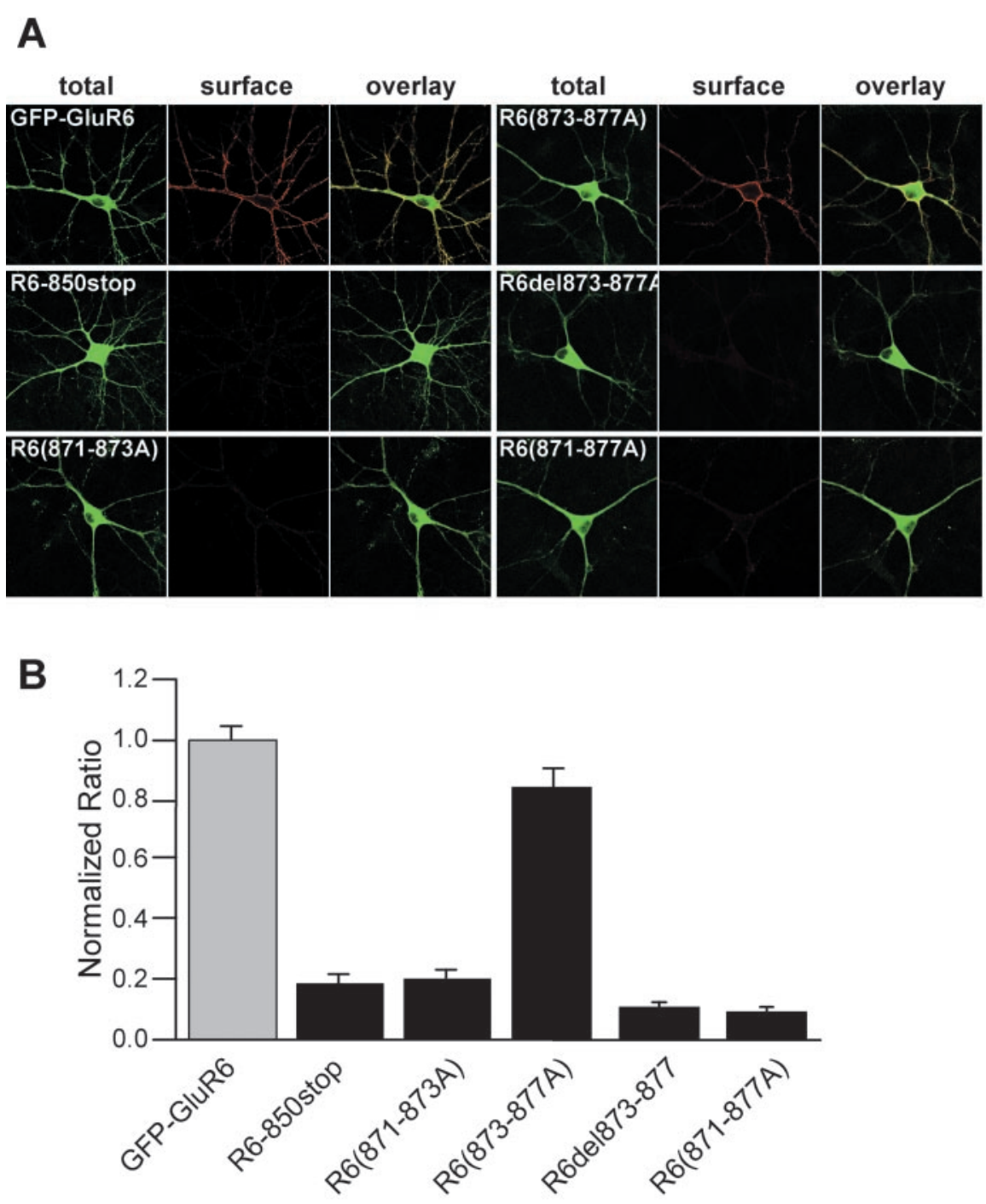

Figure 7. Residues 871-877 function as a forward trafficking determinant for GFP-GluR6 receptors in neurons. $A$, Representative fluorescent images from cultured hippocampal neurons transfected with GFP-GluR6, R6-850stop, R6(871-873A), R6(873-877A), R6del873-877, and R6(871-877A) receptors. Nonpermeabilized neurons were incubated with anti-GFP antilevels on the plasma membrane. R6 $(873-877 \mathrm{~A})$ receptors also trafficked efficiently to the surface in neurons, in contrast to their expression in COS-7 cells. R6 - 850stop, R6(871-873A), R6(871-877A), and R6del873-877 receptors were expressed only at fluorescence ratios and normalizing to the GFP-GluR6 ratio as detailed in Materials and Methods. GFP-GluR6 receptors were expressed efficiently on the plasma membrane by neurons, and R6(873-877A) receptors were present at only slightly lower levels whereas R6(871-877A) and R6del873-877 receptors exhibited very low surface expression ( $<10 \%$ of that of GFP-GluR6 receptors; 8-11 neurons analyzed for each construct).

loss of the $871-877$ basic domain accounts for the reduced surface expression of R6-868stop and R6-874stop receptors.

Multiple residues within the $871-877$ basic region contribute to formation of an efficient forward trafficking signal for GluR6 subunits. The marked reduction in current amplitudes observed from receptors truncated before K876 supports a critical role for this amino acid, but the single point mutation of this lysine did not have a significant effect on functional expression. Indeed, only two single alanine substitutions, R6(871A) and R6(873A), produced receptors that had measurably smaller mean current amplitudes (reduced by $\sim 20 \%$ compared with wild type). The importance of C871, Q872, and R873 to formation of the trafficking determinant was underscored by the profound reduction in 
surface expression of the triple alanine mutant R6(871-873) receptors. Combinations of two-site mutations within residues 871-873 [i.e., R6(871-872A), R6(871,873A), and R6(872$873 \mathrm{~A})$ ] revealed that all three residues contributed to the formation of the trafficking determinant, with mutation of Q872 and R873 having the most marked effect on surface expression (a reduction by $50 \%)$. As well, the double alanine mutants R6(874875A) and R6(876-877A) exhibited mean current amplitudes that were significantly smaller than wild type by $\sim 35 \%$. Alanine substitution or excision of five residues of the trafficking domain [R6(873-877A) and $\mathrm{R} 6 \mathrm{del}(873-877)]$ produced receptors that were functionally expressed at $20 \%$ of the level of GFP-GluR6; the similar mean amplitudes of these two mutants demonstrated that alanine substitution reduced trafficking efficiency to the same degree as complete deletion of the residues. In summary, these overlapping mutations demonstrate that the trafficking determinant is composed of multiple residues distributed between C871 and H877, with specific residues (C871, Q872, R873, and K876) playing particularly important roles.

The mechanism by which the CQRRLKH motif functions as a forward trafficking signal is unknown, but the combination of a cysteine and multiple basic residues resembles domains with similar trafficking functions in other proteins. Cysteine 871 is one of two such residues known to be palmitoylated in the GluR6 C-terminal tail (Pickering et al., 1995), but the functional relevance of this modification is unknown. Fatty acylated cysteines and polybasic residues are components of Src homology 4 domains, which are critical for the binding of Src family proteins to phospholipid bilayers (Resh, 1999). This role is not limited to Src proteins, because cysteine/polybasic domains subserve similar functions in a wide range of proteins. For example, cysteine palmitoylation in the $\mathrm{C}$ terminus of the G-protein-coupled c-c chemokine receptor type 5 (CCR5) is a critical component of a bipartite forward trafficking motif formed with a cluster of neighboring basic residues (Venkatesan et al., 2001). Palmitoylated cysteines and neighboring basic residues also serve as a polarized sorting signal in the axonal membrane protein GAP-43 (El-Husseini et al., 2001). In preliminary experiments we tested the possibility that palmitoylation of cysteine 871 plays a role in forward trafficking by incubating cells transfected with GFPGluR6 receptors with 2-bromo-palmitic acid, an inhibitor of palmitoylation, for either 16 or $48 \mathrm{hr}$ before cell ELISA detection of surface GFP, but this treatment had no significant effect on surface expression of GFP-GluR6 receptors (data not shown). Thus, how membrane association or palmitoylation of the cytoplasmic tail of GluR6 subunits promotes surface expression remains unknown, but we consider this an attractive hypothesis given that most trafficking motifs that contain basic residues (e.g., dilysine and polybasic motifs) function as ER retention and retrieval signals rather than promoting forward trafficking in the biosynthetic pathway (Keller et al., 1992; Cosson and Letourneur, 1994; Zerangue et al., 1999).

C-terminal splice variants of kainate receptor subunits differ markedly in their level of functional expression in HEK 293 cells and therefore likely contain selective trafficking determinants within the distinct splice isoforms (Sommer et al., 1992; Schiffer et al., 1997). One such determinant, an arginine-based retention/ retrieval motif (RXR), was identified recently in the KA2 kainate receptor subunit and reliably ensures that KA2 subunits do not reach the surface as homomultimeric receptors (Ren et al., 2003). Alanine mutation of the arginine domain greatly increased surface expression of homomeric KA2 receptors; however, the surface-expressed homomeric KA2 receptors still did not gate current in response to glutamate, demonstrating that an additional bar to channel gating serves to prevent activation of KA2 receptors that escape ER retrieval (Ren et al., 2003). Chimeric KA2 subunits with a GluR6 C terminus (myc-KA2 $\Delta$ R6) trafficked efficiently to the plasma membrane, and our current results demonstrate that forward trafficking of this chimeric receptor relied on the $871-877$ basic trafficking motif.

RXR-based retention signals can be masked after oligomerization with other proteins, thereby permitting biosynthesis of functional receptors or channels. Accordingly, the observation in our study that R6-850stop/KA2 receptors are located on the plasma membrane suggests that the strong KA2 RXR retention motif is masked or inactivated in some way despite the very short C-terminal tail on R6-850stop subunit proteins (and the absence of the forward trafficking motif). Similarly, heteromeric GluR5-2a/KA2 receptors are expressed functionally despite the short GluR5-2a C-terminal domain (16 amino acids) (Dingledine et al., 1999). Both GluR5-2a and R6-850stop receptors express as homomeric receptors to a small degree on the cell surface, suggesting that there exists a weak forward trafficking signal (perhaps in the $\mathrm{N}$ terminus, similar to that seen in AMPA receptors) (Xia et al., 2002) or that the receptors move through a default biosynthetic pathway in the absence of any modulatory sites in the C-terminal tail. These observations suggest that the GluR6 C-terminal tail does not sterically mask the KA2 RXR motif in heteromeric receptors. We favor the interpretation, on the basis of these data and those in the previous study on the KA2 RXR motif (Ren et al., 2003), that the KA2 RXR retention motif is inactivated as a result of multimeric receptor assembly, possibly by conformational rearrangements of the KA2 subunit itself. The nature of these putative conformational changes remains unknown.

C-terminal basic residues function as critical determinants of forward trafficking in the AMPA receptor subunits as well as kainate receptors. Surface expression of GluR1 and GluR4 AMPA receptor subunits is dependent on interactions with the spectrinbinding protein $4.1 \mathrm{~N}$ (and other protein 4.1 isoforms) (Shen et al., 2000; Coleman et al., 2003). The residues critical for this interaction reside in the juxtamembrane segment of the C-terminal domain of these AMPA receptor subunits, which bears some similarity to the trafficking motif identified in the current study for GluR6. Mutation of three basic residues in the juxtamembrane domain of the GluR4 subunit greatly reduced surface expression (to $28 \%$ of wild-type levels), whereas single point mutation of a neighboring cysteine did not reduce surface expression (Coleman et al., 2003). As with the basic domain in GluR6, the mechanisms by which protein 4.1 stabilizes (or promotes) surface expression of GluR1 and GluR4 are unknown.

Synaptic expression of neuronal kainate receptors is probably a tightly controlled process that depends on interactions with specific chaperones and scaffolding proteins that remain mostly uncharacterized. For example, kainate receptors are expressed in all of the principal neurons of the hippocampus yet show a remarkable specificity in their localization to postsynaptic sites of only a single type of excitatory synapse, the mossy fiber synapses on proximal dendrites of CA3 pyramidal neurons (Castillo et al., 1994; Vignes and Collingridge, 1997). Kainate receptors are also located near presynaptic release sites (Darstein et al., 2003) and on mossy fibers, the granule cell axons (Contractor et al., 2000; Kamiya and Ozawa, 2000; Schmitz et al., 2000), but not at postsynaptic sites on the dendrites of granule cells (A. Contractor and G. T. Swanson, unpublished results). A number of PDZ domain proteins interact with particular C-terminal splice variants 
of GluR5 and GluR6 to regulate their channel kinetics and synaptic expression. Interactions with PSD-95 (postsynaptic density-95)/SAP90 (synapse-associated protein-90) subtly altered desensitization kinetics of homomeric GluR6 or heteromeric GluR6/KA2 kainate receptors in heterologous expression systems (Garcia et al., 1998; Bowie et al., 2003). Other proteins, GRIP, PICK-1, and syntenin, bind to the PDZ binding motifs of GluR5 and GluR6 subunits. Disruption of these interactions in hippocampal CA3 pyramidal cells resulted in a gradual reduction in kainate EPSCs and an increase in AMPA EPSCs (Hirbec et al., 2003), suggesting that synaptic kainate and AMPA receptors are differentially regulated by their interactions with type II PDZ proteins and protein kinase $\mathrm{C}$ (for review, see Collingridge and Isaac, 2003). In addition, GluR6-containing kainate receptors interact with $\beta$-cadherin adhesion complexes, which might be important for localization of the receptors to mossy fiber synapses (Coussen et al., 2002). Thus, some common players have emerged in the protein-mediated regulation of synaptic AMPA and kainate receptors, although the functional effects of these interactions appear to be quite distinct.

In summary, we identified a critical determinant of the subcellular processing of kainate GluR6-containing kainate receptors. It will be of interest to determine how the basic domain interacts with trafficking determinants in other subunits, because neuronal kainate receptors are likely formed from heteromeric arrangements of subunits. Systematic approaches to identifying trafficking determinants might further identify motifs responsible for selective synaptic targeting (at mossy fiber synapses), synaptic exclusion (e.g., from Schaffer collateral-CA1 pyramidal cell synapses), or polarized targeting of kainate receptors to axons and dendrites.

\section{References}

Bowie D, Garcia EP, Marshall J, Traynelis SF, Lange GD (2003) Allosteric regulation and spatial distribution of kainate receptors bound to ancillary proteins. J Physiol (Lond) 547:373-385.

Castillo PE, Weisskopf MG, Nicoll RA (1994) The role of $\mathrm{Ca}^{2+}$ channels in hippocampal mossy fiber synaptic transmission and long-term potentiation. Neuron 12:261-269.

Coleman SK, Cai C, Mottershead DG, Haapalahti JP, Keinanen K (2003) Surface expression of GluR-D AMPA receptor is dependent on an interaction between its C-terminal domain and a 4.1 protein. J Neurosci 23:798-806.

Collingridge GL, Isaac JT (2003) Functional roles of protein interactions with AMPA and kainate receptors. Neurosci Res 47:3-15.

Contractor A, Swanson GT, Sailer A, O'Gorman S, Heinemann SF (2000) Identification of the kainate receptor subunits underlying modulation of excitatory synaptic transmission in the CA3 region of the hippocampus. J Neurosci 20:8269-8278.

Cosson P, Letourneur F (1994) Coatomer interaction with di-lysine endoplasmic reticulum retention motifs. Science 263:1629-1631.

Coussen F, Normand E, Marchal C, Costet P, Choquet D, Lambert M, Mege RM, Mulle C (2002) Recruitment of the kainate receptor subunit glutamate receptor 6 by cadherin/catenin complexes. J Neurosci 22:6426-6436.

Darstein M, Petralia RS, Swanson GT, Wenthold RJ, Heinemann SF (2003) Distribution of kainate receptor subunits at hippocampal mossy fiber synapses. J Neurosci 23:8013-8019.

Dingledine R, Borges K, Bowie D, Traynelis SF (1999) The glutamate receptor ion channels. Pharmacol Rev 51:7-62.

El-Husseini AE, Craven SE, Brock SC, Bredt DS (2001) Polarized targeting of peripheral membrane proteins in neurons. J Biol Chem 276:44984-44992.

Falquet L, Pagni M, Bucher P, Hulo N, Sigrist CJ, Hofmann K, Bairoch A (2002) The PROSITE database, its status in 2002. Nucleic Acids Res 30:235-238.

Garcia EP, Mehta S, Blair LA, Wells DG, Shang J, Fukushima T, Fallon JR, Garner CC, Marshall J (1998) SAP90 binds and clusters kainate receptors causing incomplete desensitization. Neuron 21:727-739.

Hayashi Y, Shi SH, Esteban JA, Piccini A, Poncer JC, Malinow R (2000)
Driving AMPA receptors into synapses by LTP and CaMKII: requirement for GluR1 and PDZ domain interaction. Science 287:2262-2267.

Herb A, Burnashev N, Werner P, Sakmann B, Wisden W, Seeburg PH (1992) The KA-2 subunit of excitatory amino acid receptors shows widespread expression in brain and forms ion channels with distantly related subunits. Neuron 8:775-785.

Hirbec H, Francis JC, Lauri SE, Braithwaite SP, Coussen F, Mulle C, Dev KK, Couthino V, Meyer G, Isaac JT, Collingridge GL, Henley JM (2003) Rapid and differential regulation of AMPA and kainate receptors at hippocampal mossy fibre synapses by PICK1 and GRIP. Neuron 37:625-638.

Hollmann M, Heinemann S (1994) Cloned glutamate receptors. Annu Rev Neurosci 17:31-108.

Kamiya H, Ozawa S (2000) Kainate receptor-mediated presynaptic inhibition at the mouse hippocampal mossy fibre synapse. J Physiol (Lond) 523:653-665.

Keller BU, Hollmann M, Heinemann S, Konnerth A (1992) Calcium influx through subunits GluR1/GluR3 of kainate/AMPA receptor channels is regulated by cAMP dependent protein kinase. EMBO J 11:891-896.

Ma D, Zerangue N, Raab-Graham K, Fried SR, Jan YN, Jan LY (2002) Diverse trafficking patterns due to multiple traffic motifs in $G$ proteinactivated inwardly rectifying potassium channels from brain and heart. Neuron 33:715-729.

Madden DR (2002) The structure and function of glutamate receptor ion channels. Nat Rev Neurosci 3:91-101.

Malinow R, Malenka RC (2002) AMPA receptor trafficking and synaptic plasticity. Annu Rev Neurosci 25:103-126.

Margeta-Mitrovic M, Jan YN, Jan LY (2000) A trafficking checkpoint controls GABA(B) receptor heterodimerization. Neuron 27:97-106.

Murthy VN, Sejnowski TJ, Stevens CF (1997) Heterogeneous release properties of visualized individual hippocampal synapses. Neuron 18:599-612.

Nishimune A, Isaac JT, Molnar E, Noel J, Nash SR, Tagaya M, Collingridge GL, Nakanishi S, Henley JM (1998) NSF binding to GluR2 regulates synaptic transmission. Neuron 21:87-97.

Nong Y, Huang YQ, Ju W, Kalia LV, Ahmadian G, Wang YT, Salter MW (2003) Glycine binding primes NMDA receptor internalization. Nature 422:302-307.

Pagano A, Rovelli G, Mosbacher J, Lohmann T, Duthey B, Stauffer D, Ristig D, Schuler V, Meigel I, Lampert C, Stein T, Prezeau L, Blahos J, Pin J, Froestl W, Kuhn R, Heid J, Kaupmann K, Bettler B (2001) C-terminal interaction is essential for surface trafficking but not for heteromeric assembly of GABA(b) receptors. J Neurosci 21:1189-1202.

Pickering DS, Taverna FA, Salter MW, Hampson DR (1995) Palmitoylation of the GluR6 kainate receptor. Proc Natl Acad Sci USA 92:12090-12094.

Ren Z, Riley NJ, Garcia EP, Sanders JM, Swanson GT, Marshall J (2003) Multiple trafficking signals regulate kainate receptor KA2 subunit surface expression. J Neurosci 23:6608-6616.

Resh MD (1999) Fatty acylation of proteins: new insights into membrane targeting of myristoylated and palmitoylated proteins. Biochim Biophys Acta 1451:1-16.

Schiffer HH, Swanson GT, Heinemann SF (1997) Rat GluR7 and a carboxyterminal splice variant, GluR7b, are functional kainate receptor subunits with a low sensitivity to glutamate. Neuron 19:1141-1146.

Schmitz D, Frerking M, Nicoll RA (2000) Synaptic activation of presynaptic kainate receptors on hippocampal mossy fiber synapses. Neuron 27:327-338.

Scott DB, Blanpied TA, Swanson GT, Zhang C, Ehlers MD (2001) An NMDA receptor ER retention signal regulated by phosphorylation and alternative splicing. J Neurosci 21:3063-3072.

Shen L, Liang F, Walensky LD, Huganir RL (2000) Regulation of AMPA receptor GluR1 subunit surface expression by a $4.1 \mathrm{~N}$-linked actin cytoskeletal association. J Neurosci 20:7932-7940.

Shi S, Hayashi Y, Esteban JA, Malinow R (2001) Subunit-specific rules governing AMPA receptor trafficking to synapses in hippocampal pyramidal neurons. Cell 105:331-343.

Sommer B, Burnashev N, Verdoorn TA, Keinänen K, Sakmann B, Seeburg PH (1992) A glutamate receptor channel with high affinity for domoate and kainate. EMBO J 11:1651-1656.

Song I, Kamboj S, Xia J, Dong H, Liao D, Huganir RL (1998) Interaction of 
the $N$-ethylmaleimide-sensitive factor with AMPA receptors. Neuron 21:393-400.

Standley S, Roche KW, McCallum J, Sans N, Wenthold RJ (2000) PDZ domain suppression of an ER retention signal in NMDA receptor NR1 splice variants. Neuron 28:887-898.

Swanson GT, Heinemann SF (1998) Heterogeneity of homomeric GluR5 kainate receptor desensitization expressed in HEK293 cells. J Physiol (Lond) 513:639-646.

Traynelis SF, Wahl P (1997) Control of rat GluR6 glutamate receptor open probability by protein kinase A and calcineurin. J Physiol (Lond) 503:513-531.

Venkatesan S, Petrovic A, Locati M, Kim YO, Weissman D, Murphy PM (2001) A membrane-proximal basic domain and cysteine cluster in the C-terminal tail of CCR 5 constitute a bipartite motif critical for cell surface expression. J Biol Chem 276:40133-40145.
Vignes M, Collingridge GL (1997) The synaptic activation of kainate receptors. Nature 388:179-182.

Xia H, von Zastrow M, Malenka RC (2002) A novel anterograde trafficking signal present in the N-terminal extracellular domain of ionotropic glutamate receptors. J Biol Chem 277:47765-47769.

Xia Z, Dudek H, Miranti CK, Greenberg ME (1996) Calcium influx via the NMDA receptor induces immediate early gene transcription by a MAP kinase/ERK-dependent mechanism. J Neurosci 16:5425-5436.

Yaffe MB, Leparc GG, Lai J, Obata T, Volinia S, Cantley LC (2001) A motifbased profile scanning approach for genome-wide prediction of signaling pathways. Nat Biotechnol 19:348-353.

Zerangue N, Schwappach B, Jan YN, Jan LY (1999) A new ER trafficking signal regulates the subunit stoichiometry of plasma membrane K(ATP) channels. Neuron 22:537-548. 